\title{
ENSO Teleconnection Pattern Changes over the Southeastern United States under a Climate Change Scenario in CMIP5 Models
}

\author{
Ji-Hyun Oh, ${ }^{1,2}$ D. W. Shin, ${ }^{2}$ Steven D. Cocke, ${ }^{2}$ and Guillermo A. Baigorria ${ }^{3}$ \\ ${ }^{1}$ Joint Institute for Regional Earth System Science and Engineering, University of California, Los Angeles, CA 90095-7228, USA \\ ${ }^{2}$ Center for Ocean-Atmospheric Prediction Studies, Florida State University, Tallahassee, FL 32310, USA \\ ${ }^{3}$ School of Natural Resources and Department of Agronomy and Horticulture, University of Nebraska-Lincoln, Lincoln, \\ NE 68583-0968, USA \\ Correspondence should be addressed to Ji-Hyun Oh; ji-hyun.oh@jpl.nasa.gov
}

Received 15 August 2014; Accepted 31 October 2014; Published 21 December 2014

Academic Editor: Luis Gimeno

Copyright (C) 2014 Ji-Hyun Oh et al. This is an open access article distributed under the Creative Commons Attribution License, which permits unrestricted use, distribution, and reproduction in any medium, provided the original work is properly cited.

\begin{abstract}
A strong teleconnection exists between the sea surface temperature (SST) over the tropical Pacific and the winter precipitation in the southeastern United States (SE US). This feature is adopted to validate the fidelity of Coupled Model Intercomparison Project Phase 5 (CMIP5) in this study. In addition, the authors examine whether the teleconnection pattern persists in the future under a global warming scenario. Generally, most of the eight selected models show a positive correlation between November SST over Niño 3 region and December-February (DJF) mean daily precipitation anomalies over the SE US, consistent with the observation. However, the models with poor realization of skewness of Niño indices fail to simulate the realistic teleconnection pattern in the historical simulation. In the Representative Concentration Pathways 8.5 (RCP8.5) run, all of the models maintain positive and slightly increased correlation patterns. It is noteworthy that the region with strong teleconnection pattern shifts northward in the future. Increased variance of winter precipitation due to the SST teleconnection is shown over Alabama and Georgia rather than over Florida under the RCP8.5 scenario in most of the models, differing from the historical run in which the precipitation in Florida is the most attributable to the eastern Pacific SST.
\end{abstract}

\section{Introduction}

In 2008, many climate-modeling groups in the world agreed to build a new set of coordinated climate model experiments. The Coupled Model Intercomparison Project Phase 5 (CMIP5) was planned to produce a standard set of simulations from state-of-the-art models to assess the fidelity of the models in simulating the recent past, to provide projections of future climate change, and to promote our understanding of mechanisms responsible for model differences [1].

Although numerous studies have been conducted to validate the credibility of the newly launched CMIP5 data globally [2-5], regional assessments of the CMIP5 have rarely been carried out. Therefore, it is crucial to narrow our viewpoint to a regional scale. We restrict our study to the southeastern United States (SE US) including Alabama, Georgia, and Florida during wintertime in this study. The SE
US has been studied less frequently than other regions in the United States despite its unprecedented population growth during recent decades [6]. Furthermore, agriculture vulnerable to climate conditions is a major industry over the SE US, which is a large contributor to total annual US agricultural production. According to the U.S. Department of Agriculture (USDA) National Agricultural Statistics Service [7], the estimated total value of principal crops in 2012 for Alabama, Florida, and Georgia was 1.33, 4.75, and 3.94 billon US dollars, respectively. As the risk related to floods and droughts causes significant financial losses from agricultural businesses, a better understanding of climate variability and climate change in SE US is essential to build appropriate risk management and adaptation strategies in agriculture.

It is well known that the SE US has a strong teleconnection to tropical Pacific sea surface temperature (SST). Previous studies demonstrated that warmer (colder) SSTs lead to 
wetter (drier) winters in the coastal southeastern states and to the opposite signal more inland [8-10]. El Niño-Southern Oscillation (ENSO), the most significant tropical signal, influences the interannual variability in the midlatitudes, including the SE US. El Niño (La Niña) events are recognized by anomalous warming (cooling) in the eastern-to-central equatorial Pacific. Previous research has documented that changes in the SST and atmospheric circulation in the equatorial Pacific during El Niño and La Niña give rise to a shift of the subtropical and polar jet positions [11]. During El Niño phase, the shift interacts with cyclone development over the Gulf of Mexico, resulting in increased cloudiness in the SE US. On the other hand, during La Niña phase, because of the northward-shifted jet, the storm tracks tend to stay north of the SE US [11]. This prevents the cold air from reaching the region, resulting in a warmer and drier winter in the SE US. The strong ENSO teleconnection in this region has been used in the last decade to advise farmers about seasonal climate conditions to improve their climate-related discussion and decision-making [12]. Even though the highest correlations between ENSO and precipitation in the SE US region are during wintertime in the Northern Hemisphere (DJF), precipitation in this season affects seed germination and plant emergence by conditioning the available soil moisture necessary for establishing a crop. Low levels of soil moisture and late rainfall onsets affect the initial plant vigor, as well as the viability of the crop on following phenological stages and yields. By being able to predict the ENSO-based seasonal climate in the region, farmers can change planting dates and/or crop varieties to tailor water requirements to the seasonal forecast as well as buy the appropriate crop insurance to avoid losses [13]. Nevertheless, it is less clear if the global climate model (GCM) can adequately reproduce the precipitation teleconnection associated with the ENSO [14-16].

Furthermore, several studies have examined the change of teleconnection with time. For instance, Diaz et al. [17] found that the correlation between ENSO and precipitation over the SE US is higher after the 1980s. Kug et al. [18] also demonstrated a strong possibility that the local climate impact of ENSO will be different in the future. The climate change is now widely accepted as a global issue. Under the influence of global warming, the mean climate of the Pacific region will presumably undergo a significant change. Jones et al. [19] emphasized the importance of the predictability of climate and its influence on crop production. With better predictions of climate, it is possible to cope with natural hazards and to take advantage of expected favorable conditions. Although the physical mechanisms behind this temporal change have not been understood, it will be helpful for stakeholders' preparation for possible impacts of climate change over the SE US to investigate the teleconnection pattern change in the future using the CMIP5 experiments. We hypothesized that a model, which simulates realistic atmospheric response to the SST related to ENSO in the present climate, could have higher reliability than the other models with unrealistic present simulation in terms of future projections under global warming scenarios.
In this study, the fidelity of CMIP5 models in terms of simulation of regional scale climate variability and trend is assessed by comparing modeled teleconnection patterns with the observed pattern. We also investigate whether this current teleconnection will persist in the future under the global warming scenario. This paper is structured as follows. Data and method used for the analysis are described in Section 2. In Section 3, teleconnection patterns in the past and future are investigated. In addition, further validation of models by comparing skewness of model SST anomalies with observation is conducted. A summary and discussion are presented in Section 4.

\section{Data and Methods}

2.1. Data. We analyze historical and Representative Concentration Pathways 8.5 (RCP8.5) simulations produced by 8 CMIP5 models. Eight CMIP5 models are chosen for this study on the basis of their availability of key variables for crop model including precipitation, maximum and minimum surface temperature, and solar radiation so that our results can be applied to forthcoming study focusing on crop yield change under the climate scenario using the crop model. Models with too sparse resolution (both the longitude and latitude are larger than $2.5^{\circ}$ ) are not selected for this study because our domain of interest is confined to the SE US region. The model resolution, the number of ensemble members, and the total simulated years are given in Table 1. More detailed information of CMIP5 models can be found at http://cmip-pcmdi.llnl.gov/cmip5/index.html. The historical run is carried out by imposing changing solar forcing, volcanic, and anthropogenic influences from 1850 to 2005 (Geophysical Fluid Dynamics Laboratory (GFDL) models spanning from 1861 to 2005). RCP8.5 is the pathway with the highest greenhouse gas emission: the radiative forcing increases throughout the 21st century before reaching a level of about $8.5 \mathrm{~W} / \mathrm{m}^{2}$ at the end of the century. The integration for the RCP8.5 experiment spans the period of 2006-2100.

The extended reconstruction of historical sea surface temperature (ERSST) version 3 data are used to provide SST observations for the period of 1854-2010. The data are acquired from the web site http://www.esrl.noaa.gov/psd/data/gridded/data.noaa.ersst.html. Cooperative station daily precipitation data provided by the National Climate Data Center (NCDC; http://www.ncdc.noaa.gov/data-access/land -based-station-data/land-based-datasets/cooperative-observer-network-coop) are also utilized for validation of the model simulations in this study. This is the "Data Set 3200", or "Surface Land Daily Cooperative Summary of the Day," coming from thousands of volunteers that took observation in US and the extensive quality controlled data are available at NCDC's web site: http://cdo.ncdc.noaa.gov.

2.2. Methods. Through application of a bilinear interpolation method [20], which is a simplified statistical downscaling method [21], daily precipitation datasets from the CMIP5 models and station data are interpolated to $20 \mathrm{~km}$ spatial resolution for easy comparison between the observed station 
TABLE 1: CMIP5 model names and specifications.

\begin{tabular}{|c|c|c|c|c|c|c|}
\hline \multirow[t]{2}{*}{ Model } & \multirow[t]{2}{*}{ Institution } & \multirow[t]{2}{*}{ ID } & \multirow[t]{2}{*}{ AM resolution } & \multicolumn{2}{|c|}{$\begin{array}{l}\text { Integration period } \\
\text { (years) }\end{array}$} & \multirow{2}{*}{$\begin{array}{l}\text { Number of } \\
\text { ensembles }\end{array}$} \\
\hline & & & & Historical & RCP8.5 & \\
\hline CCSM4 & $\begin{array}{l}\text { National Center for } \\
\text { Atmospheric Research }\end{array}$ & 1 & $0.9^{\circ}$ Lat $\times 1.25^{\circ}$ Lon & 156 & 95 & 2 \\
\hline CSIRO-Mk3-6-0 & $\begin{array}{l}\text { CSIRO (Commonwealth } \\
\text { Scientific and Industrial } \\
\text { Research Organisation, } \\
\text { Australia) and BOM } \\
\text { (Bureau of Meteorology, } \\
\text { Australia) }\end{array}$ & 2 & T63 & 145 & 95 & 10 \\
\hline GFDL-CM3 & $\begin{array}{l}\text { Geophysical Fluid } \\
\text { Dynamics Laboratory }\end{array}$ & 3 & $144 \times 90: 2.0^{\circ}$ Lat $\times 2.5^{\circ}$ Lon & 145 & 95 & 1 \\
\hline GFDL-ESM2G & $\begin{array}{l}\text { Geophysical Fluid } \\
\text { Dynamics Laboratory }\end{array}$ & 4 & $144 \times 90: 2.0^{\circ}$ Lat $\times 2.5^{\circ}$ Lon & 145 & 95 & 1 \\
\hline GFDL-ESM2M & $\begin{array}{l}\text { Geophysical Fluid } \\
\text { Dynamics Laboratory }\end{array}$ & 5 & $144 \times 90: 2.0^{\circ}$ Lat $\times 2.5^{\circ}$ Lon & 156 & 95 & 1 \\
\hline MIROC5 & $\begin{array}{l}\text { Atmosphere and Ocean } \\
\text { Research Institute (The } \\
\text { University of Tokyo), } \\
\text { National Institute } \\
\text { for Environmental Studies, } \\
\text { and Japan Agency for } \\
\text { Marine-Earth Science and } \\
\text { Technology }\end{array}$ & 6 & T85 & 156 & 95 & 3 \\
\hline MPI-ESM-LR & $\begin{array}{l}\text { Max Planck Institute for } \\
\text { Meteorology (MPI-M) }\end{array}$ & 7 & T63 & 156 & 95 & 3 \\
\hline NorESM1-M & Norwegian Climate Centre & 8 & $0.9^{\circ}$ Lat $\times 1.25^{\circ}$ Lon & 156 & 95 & 1 \\
\hline
\end{tabular}

and model precipitation data. This enables us to conduct more intensive analysis on our domain of interest.

To examine the strength of the teleconnection between the SST over the tropical Pacific and the winter precipitation in the southeastern United States, we compute correlation coefficient $(r)$ between Niño 3 index in November and December-February (DJF) mean daily precipitation anomalies as follows:

$$
r=\frac{\sum\left(x_{i}-\bar{x}\right)\left(y_{i}-\bar{y}\right)}{\sqrt{\left[\sum\left(x_{i}-\bar{x}\right)^{2}\right]\left[\sum\left(y_{i}-\bar{y}\right)^{2}\right]}},
$$

where $x$ is Niño 3 index in November and $y$ is DJF mean daily precipitation anomalies. Here, monthly SST anomalies averaged over the Niño 3 region $\left(5^{\circ} \mathrm{N}-5^{\circ} \mathrm{S}, 150^{\circ} \mathrm{W}-90^{\circ} \mathrm{W}\right)$ are referred to as the Niño 3 index. Monthly climatology by averaging over each calendar month in the time series and the trend for the analysis period are removed from SST data.

Although various different methods have been used to specify when El Niño or La Niña events have occurred, Japan Meteorological Agency (JMA) index is utilized to classify ENSO events into El Niño, neutral, and La Niña phases following Hanley et al. [22]. The index is based on the monthly SST anomalies in the region $4^{\circ} \mathrm{S}$ to $4^{\circ} \mathrm{N}, 150^{\circ} \mathrm{W}$ to $90^{\circ} \mathrm{W}$, which is nearly similar to the Niño 3 region. The anomalies are filtered via a five-month running mean. The JMA definition for an El Niño (La Niña) event requires SST in the JMA region to be greater (less) than a threshold for six consecutive months and the months must include OctoberNovember-December (OND). In this study, the thresholds are determined using the SST of each CMIP5 model. The monthly anomalies are sorted; the value corresponding to the 75th percentile is selected for El Niño year's threshold, and the value corresponding to the 25 th percentile is chosen for La Niña year's threshold.

Burgers and Stephenson [23] suggested that skewness could be a useful tool for validating models. The skewness represents the asymmetry of a probability density function (PDF), which is zero for a normal distribution. It is defined as

$$
\text { skewness }=\frac{(1 / n) \sum_{i=1}^{n}\left(x_{i}-\bar{x}\right)^{3}}{\left((1 / n) \sum_{i=1}^{n}\left(x_{i}-\bar{x}\right)^{2}\right)^{2 / 3}},
$$

where $x_{i}$ is $i$ th data value, $\bar{x}$ is the mean, and $n$ is number of data points. A PDF with positive (negative) skewness has heavier tails on the positive (negative) anomaly side of the mean. Positive (negative) skewness has greater (less) mean and median than mode. In addition to Niño 3, Niño 3.4 (SST anomalies averaged over $5^{\circ} \mathrm{N}-5^{\circ} \mathrm{S}, 170^{\circ} \mathrm{W}-120^{\circ} \mathrm{W}$ ) and Niño 4 (SST anomalies averaged over $5^{\circ} \mathrm{N}-5^{\circ} \mathrm{S}, 160^{\circ} \mathrm{E}-150^{\circ} \mathrm{W}$ ) indices are also utilized for this study to investigate the skewness of SST over each Niño region regarding CMIP5 models' performance of simulating the SST over the equatorial Pacific Ocean. 


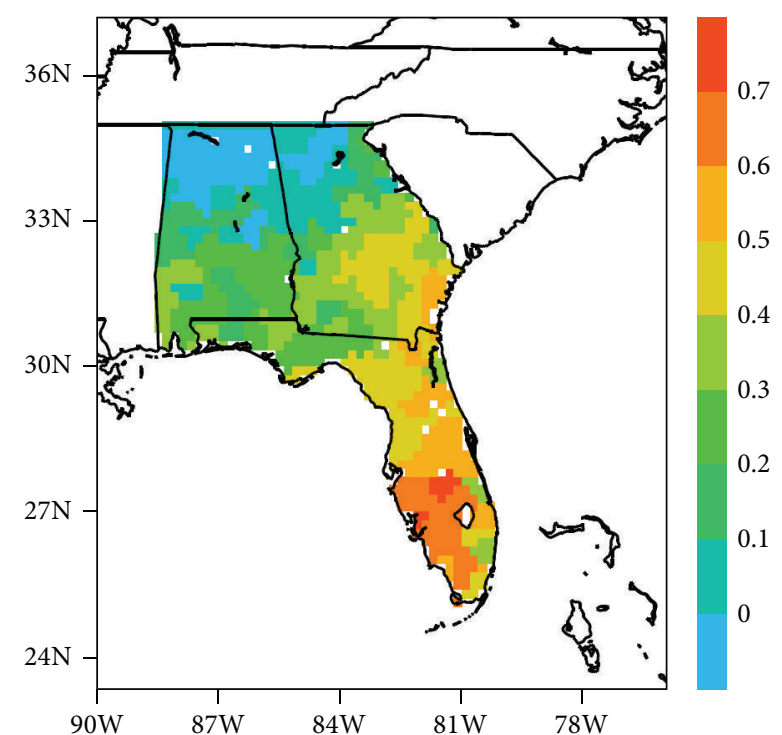

Figure 1: Temporal correlation between November Niño 3 index and the observed rainfall (DJF mean) for 1970-2010: a correlation with the absolute value greater than 0.3 is statistically significant at the $95 \%$ confidence level.

\section{Results}

3.1. Teleconnection Patterns over the SE US: Historical and RCP8.5 Simulations. The SE US has a robust interannual predictability of the precipitation because of the strong teleconnection to the tropical Pacific SST. This distinct feature is applied to the assessment of the CMIP5 models in this study. Figure 1 shows the correlations between the observed DJF mean daily precipitation anomalies and the November Niño 3 index based on ERSST for the period of 1970 to 2010. Figure 1 illustrates that warmer (colder) SSTs in November lead to wetter (drier) winters in SE US, which demonstrates the strong teleconnection between tropical Pacific SST and winter precipitation over Florida and southeastern Georgia in particular. Florida shows the highest value of correlation coefficient, whereas Alabama displays the lowest value (less than critical value 0.3 at $95 \%$ confidence level) among the three states of the SE US.

Comparing this prominent feature in the observation to that in the CMIP5 simulations, we are able to assess the credibility of CMIP5 models implicitly. Figure 2 shows the modeled teleconnection of DJF mean daily precipitation anomalies over the SE US to the November Niño 3 index derived from each model. On the basis of the results from the historical run (Figures 2(a)-2(h)), we further examine teleconnection patterns under the future climate scenario, RCP8.5 (Figures 2(i)-2(p)). For the model having ensemble members, the ensemble mean of the correlations is adopted. Looking at the correlations of the historical experiment, we find that most of the models show a positive correlation between the Niño 3 SST in November and the DJF mean daily precipitation anomalies over the SE US, consistent with the observation. It is of particular interest to note that the GFDL Climate Model version 3 (GFDL-CM3; Figure 2(c)) model shows the strongest teleconnection with the largest value of 0.7 in northern Florida, whereas the GFDL Earth System Model (GFDL-ESM2G; Figure 2(d)) displays the weakest teleconnection, with 0.3 for the smallest value among GFDL models. CM3 is designed to address emerging issues in climate change, including aerosol-cloud interactions, chemistry-climate interactions, and coupling between the troposphere and stratosphere [24]. ESM is a coupled global carbon-climate Earth System Model developed to advance understanding of how the earth's biogeochemical cycles, including human actions, interact with the climate system [24]. On the other hand, ESM2G and ESM2M differ in the physical ocean component. In ESM2M, pressure-based vertical coordinates are used along the developmental path of GFDL's Modular Ocean Model version 4.1. In ESM2G, an independently developed isopycnal model using the generalized ocean layer dynamics (GOLD) code base is used (http://www.gfdl.noaa.gov/earth-system-model). Dunne et al. [24] documented that ESM2M has an overly strong El Niño-Southern Oscillation, whereas weak ENSO is represented in ESM2G. The weaker correlation of GFDLESM2G than that of GFDL-ESM2M (Figure 2(e)) seems to be attributable to the capability of the model in representing ENSO. This demonstrates that one partial change in the model could contribute to different teleconnection patterns. Although the value of correlation coefficient slightly differs among the models, the winter precipitation in Florida tends to have closer relationship with the Pacific SST than the precipitation in Georgia and Alabama in most of the models. However, GFDL-ESM2G (Figure 2(d)) and MPI-ESM-LR (Figure 2(g)) have slightly reduced correlation over Florida compared to the other two states, which is also inconsistent with the observation. The fact that modeled correlation maps are compatible with the observed map shown in Figure 1 implies that the global models in the CMIP5 are capable of simulating the regional response of the teleconnection. We expect that the models that simulate more realistic teleconnection patterns in the historical run may project more possible features of teleconnection patterns under the global climate change scenario.

On the basis of the results from the historical run, we further examine teleconnection patterns under the future climate scenario, RCP8.5. The right column in Figure 2 shows correlation maps of the RCP8.5 experiment. In the RCP8.5 run, all of the models maintain the positive correlation patterns. This denotes that the current teleconnection pattern will persist under the global warming scenario. However, changes in the value of correlation coefficient exist over the domain compared to the pattern in the historical simulation. While CSIRO-Mk3-6-0 (Figures 2(b), 2(j)) shows a decrease in the correlation over the analysis domain in the future run, GFDL-CM3 (Figures 2(c), 2(k)) displays a striking increase in the correlation, especially over Alabama and Georgia.

Figure 3 shows explained variances averaged separately over Alabama, Georgia, and Florida. The left figure shows the result from the historical run, and the right figure shows the result from the RCP8.5 run. The percentage of variance is defined by the square of correlation coefficient $(r)$ shown in Figures 1 and 2 multiplied by 100. For example, the observed coefficient 0.7 over Florida in Figure 1 implies that the SST 


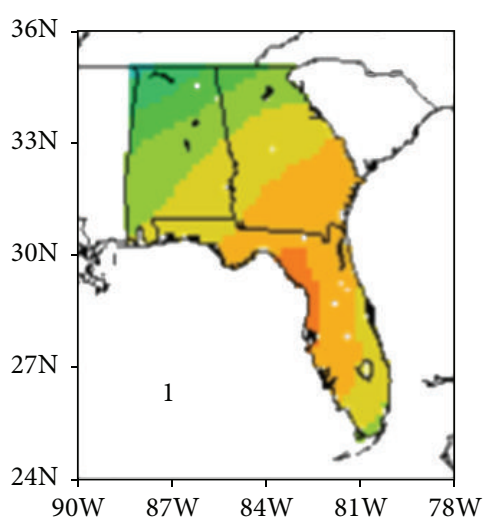

(a)

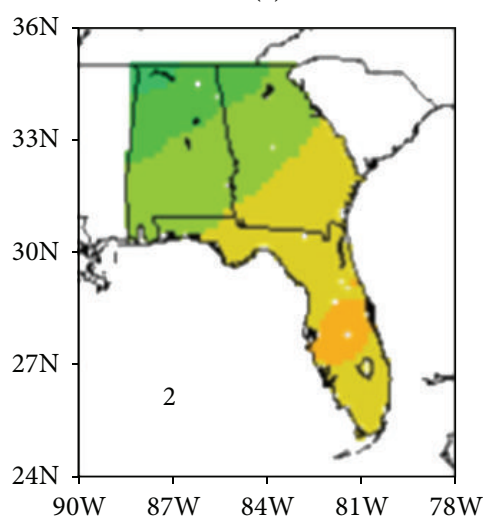

(b)

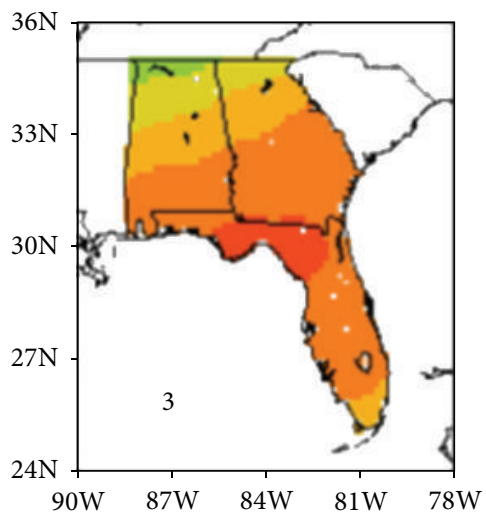

(c)

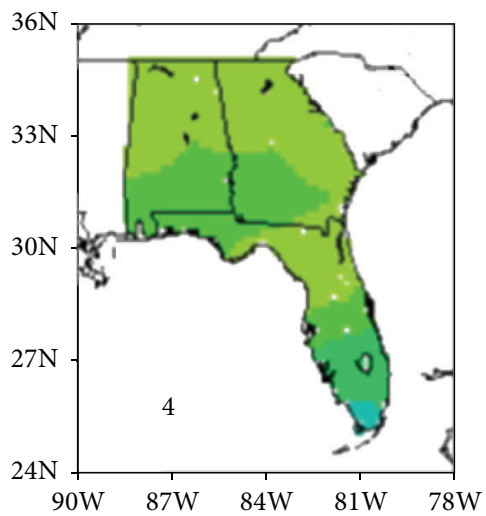

(d)

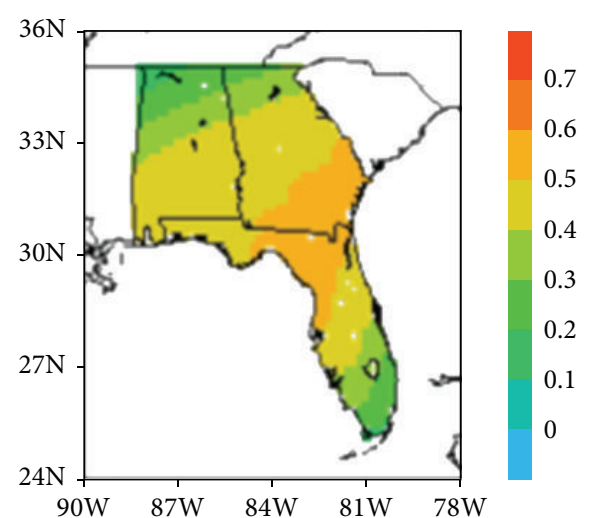

(i)

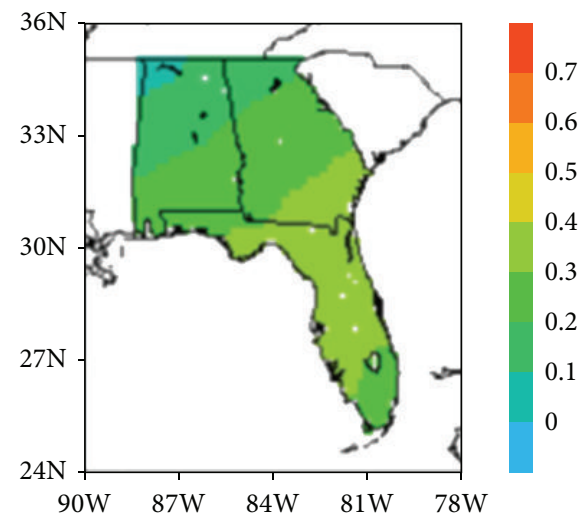

(j)

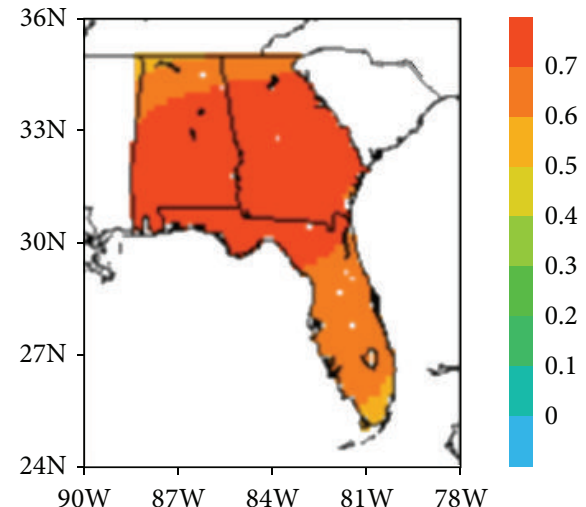

(k)

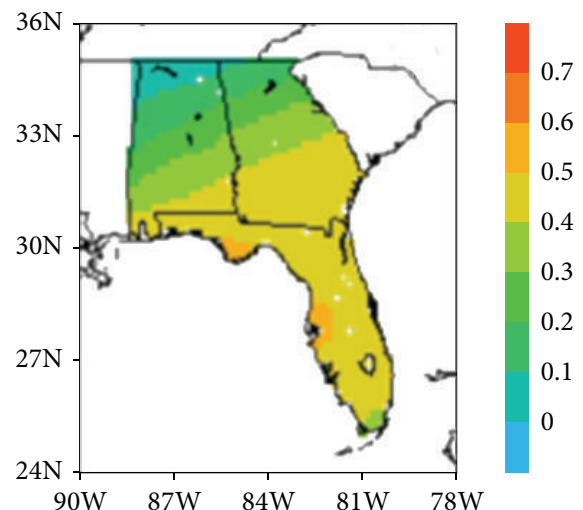

(l)

FIgUre 2: Continued. 

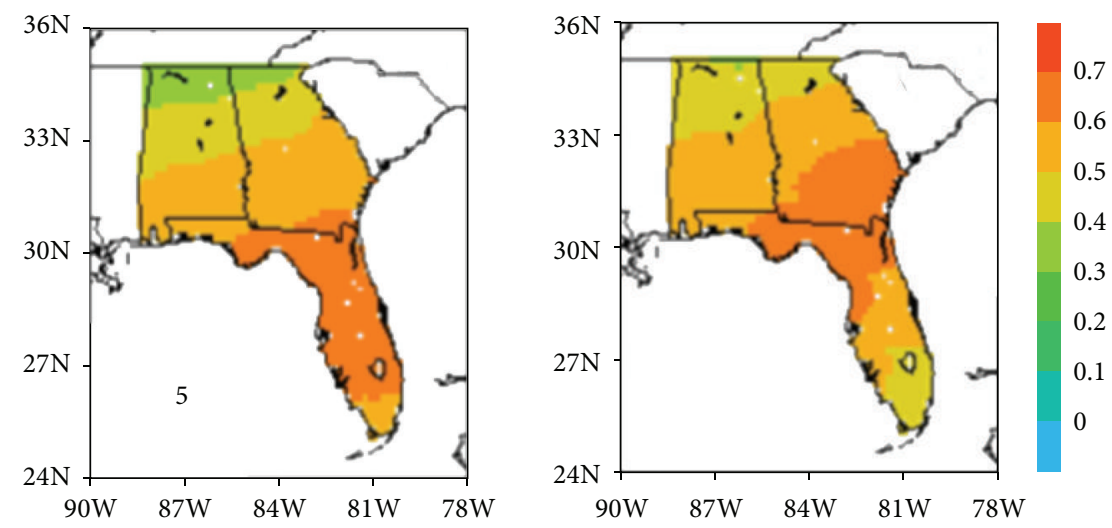

(e)

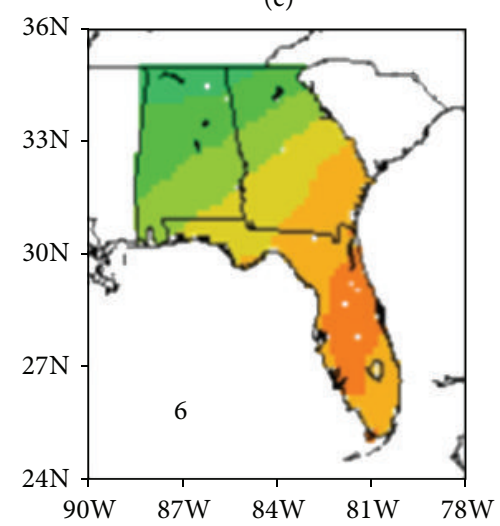

(m)

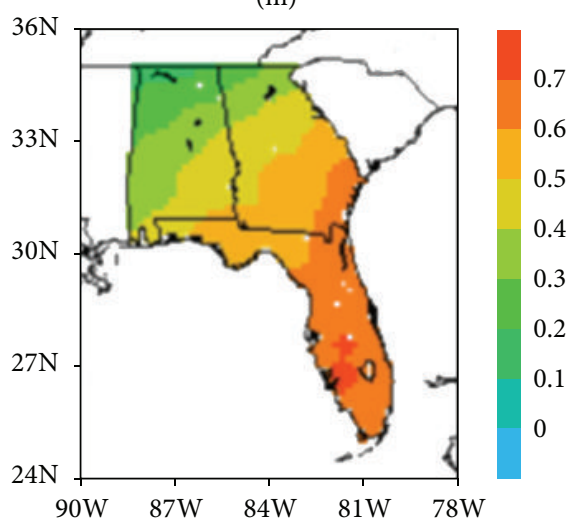

(f)

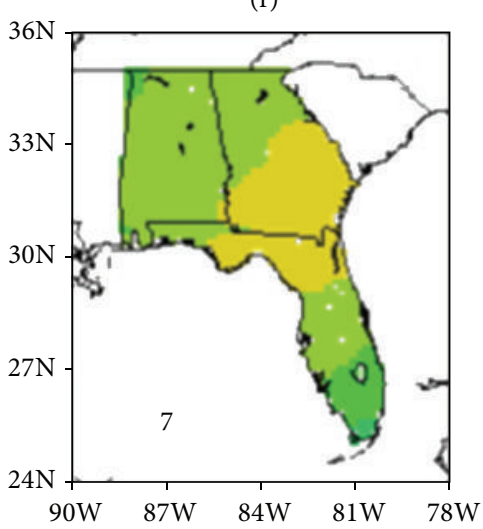

(n)

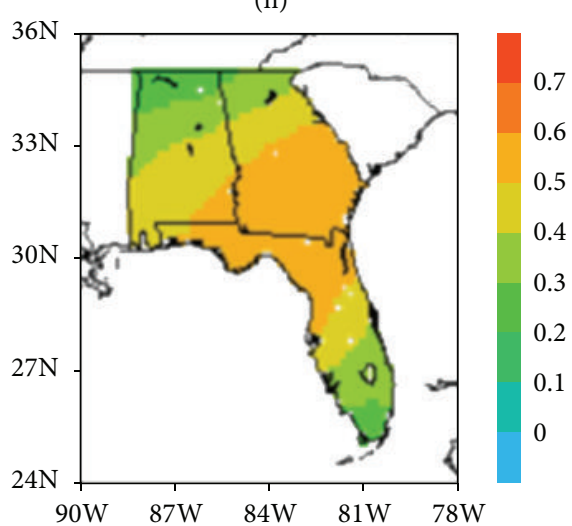

(g)

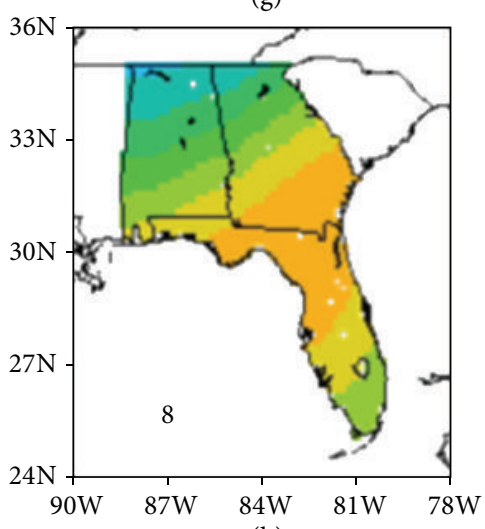

(o)

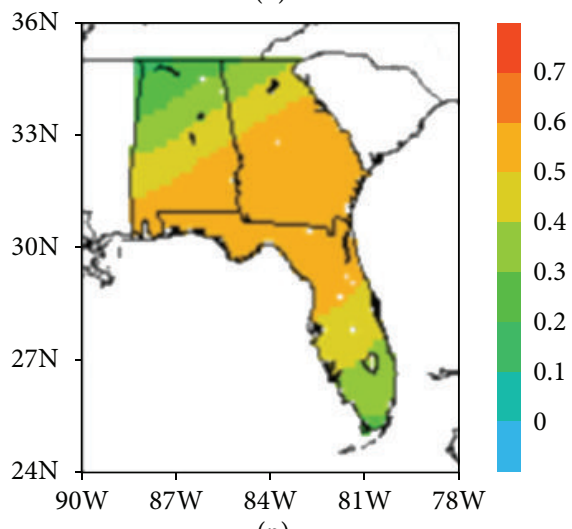

(p)

FIGURE 2: Temporal correlations between November Niño 3 index and the DJF mean daily precipitation anomalies for historical (a-h) and RCP8.5 (i-p) experiments from CMIP5 models. Each model is identified by ID number as in Table 1. 


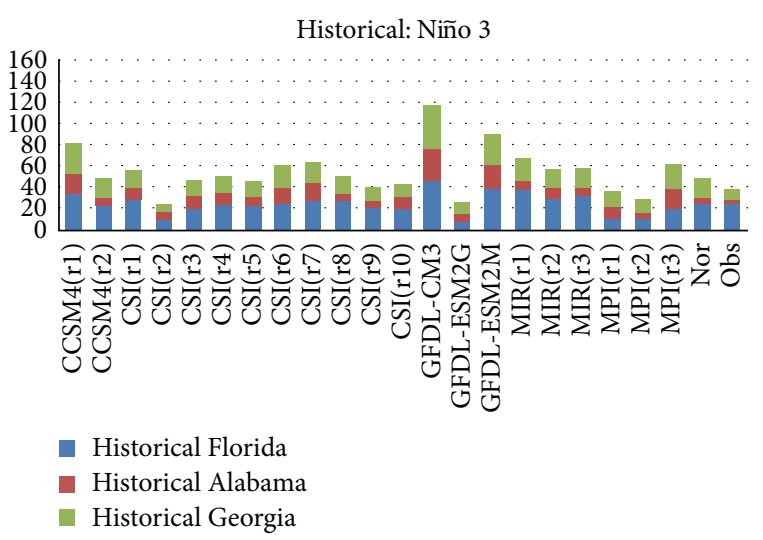

(a)

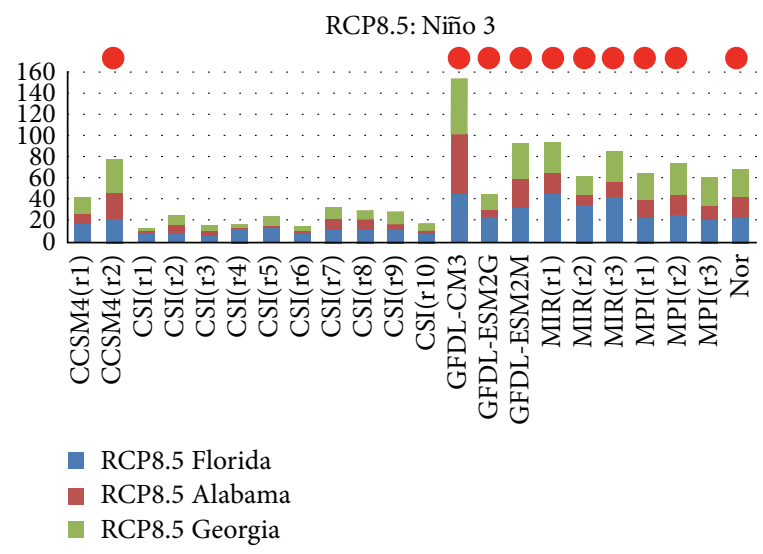

(b)

FIGURE 3: Stacked explained variances (\%) for historical (a) and RCP8.5 (b) experiments from CMIP5 models, respectively. Explained variance is averaged over the States of Florida, Alabama, and Georgia, separately. All ensemble members are presented in the diagram. Observed value is included in (a) at the rightmost column.

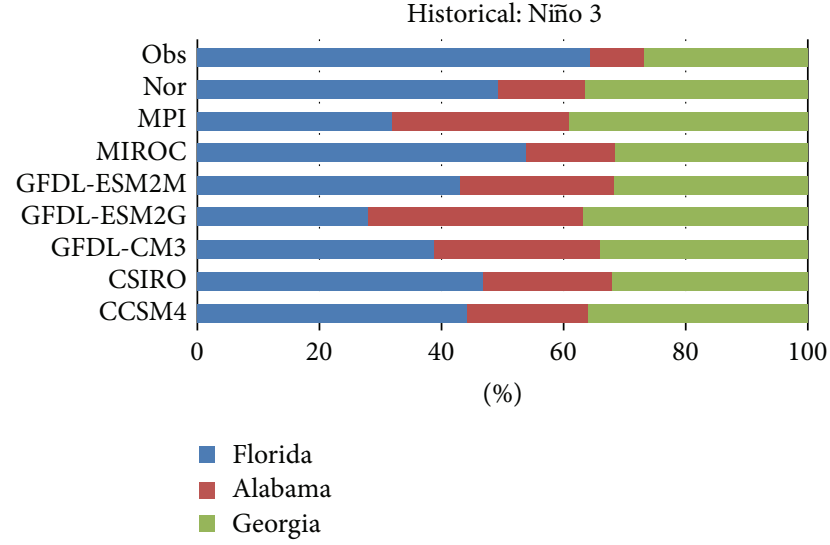

(a)

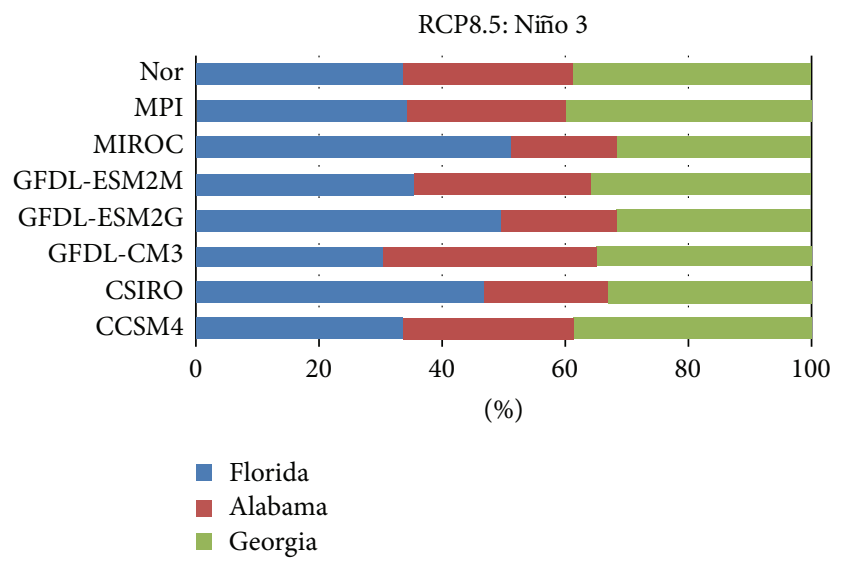

(b)

FIgURE 4: Percentage of the explained variance of Florida, Alabama, and Georgia contributes to a total explained variance of southeastern US spanning 3 states for historical (a) and RCP8.5 (b) experiments from CMIP5 models.

over the Niño 3 region accounts for $49 \%$ of the variance of winter precipitation over the region. The explained variance of each state is stacked as a column in Figure 3. By comparing the height of the columns, we can deduce the degree to which SST over Niño 3 region accounts for the variance of total DJF mean daily precipitation over each state in the observation and models. As a benchmark, the observed result is shown in a rightmost column of Figure 3(a). Whereas the SST over the Niño 3 region accounts for the largest portion of variance of the rainfall in Florida (more than 20\%) in the observation, it shows the least percentage of variance in Alabama. Most of the CMIP5 models analyzed in this study show this feature despite different column heights. Among the eight CMIP5 models in the historical experiment, GFDL-CM3 shows the tallest column, indicating three times larger explained variance than the observation. In contrast, GFDL-ESM2G shows the shortest column. GFDL-ESM2G and MPI-ESM-LR rarely show the largest proportion in
Florida, which is different from the observation. The features are consistent with the spatial teleconnection pattern shown in Figure 2.

In the RCP8.5 run (Figure 3(b)), the stronger relationship between the SST over the Niño 3 region and the DJF mean daily precipitation is projected by all of the models, except for CSIRO-Mk3-6-0. Red circles in the right figure of Figure 3 indicate the increase in the total explained variance of the RCP8.5 experiment, compared to the historical run. It is noteworthy that the total increase in the explained variance of most of the models is attributed to the increase in the explained variance over Alabama and Georgia. Figure 4 further clarifies this feature. The sum of the percentages from each state over the SE US shown in Figure 3 is converted to $100 \%$ to determine which state accounts for the largest percentage of variance of precipitation in the entire SE US. As a result, Florida accounts for more than $60 \%$ of SE US rainfall variance, which is associated with the SST over Niño 
3 region in the observation (Figure 4(a)). In the historical simulation, Florida also has the largest portion, around $40 \%$, except for the results from GFDL-ESM2G and MPI-ESMLR. However, the models that show the largest portion of rainfall in Florida in the historical run (NorESM1-M, MIROC5, GFDL-ESM2M, GFDL-CM3, and CCSM4) have an increased portion of variance in Alabama and Georgia under the RCP8.5 scenario.

To analyze the impact of ENSO on the high percentile of rainfall over the SE US during winter, we focus on the 75th percentile from the right tail of DJF daily rainfall anomalies distribution in terms of ENSO phases (i.e., El Niño, neutral, and La Niña phases) classified by the JMA index. Model-generated DJF daily precipitation is displayed on the rightmost column of Figures 5 and 6, while the spatial patterns of the 75th percentile of precipitation anomaly for El Niño, neutral, and La Niña years are in the left three columns. The area of maximum DJF mean daily rainfall amount is mostly located over the northern SE US, spanning Alabama and Georgia. Consistent with the previous correlation map, during El Niño years we have heavier 75th percentile of rainfall over the SE US; however, the magnitude of rainfall anomalies is likely to be reduced during La Niña years. Florida has greater value of the 75th percentile of rainfall anomaly for El Niño years than the other two states, differing from the DJF mean daily precipitation pattern. In the same way, smaller value of the 75th percentile of rainfall anomaly during La Niña years is mostly located over Florida. The 75th percentile of rainfall in GFDL-ESM2G (Figures 5(d), $5(\mathrm{~h})$, and 5(l)) is rarely dependent on the ENSO phase, in agreement with the small correlation pattern shown in Figure 2(d).

Figure 7 shows the difference of the rainfall amount at the 75th percentile between RCP8.5 and historical experiments by ENSO phase. The models, which show a greater correlation coefficient in the RCP8.5 than in the historical run, have larger positive value in the difference of the 75th percentile of rainfall amount during El Niño events. Interestingly, the increase of extreme rainfall amount due to the El Niño events tends to be dominant over the northern regions of the SE US, including Alabama and Georgia, as discussed earlier (Figures $2-4)$. In contrast, during La Niña events these models show negative value in the difference of rainfall amount due to the teleconnection. However, the decrease in the rainfall amount is not solely concentrated over the northern domain, which supports the hypothesis that the teleconnection associated with El Niño is not a mirror image of La Niña [25].

3.2. Relationship between SE US Winter Precipitation and Pacific SST. We have examined the teleconnection between the SST over the eastern Pacific in November and the following wintertime precipitation over the SE US. Figures 8 and 9 display the correlation between the November SST over the entire Pacific and the following DJF mean daily rainfall anomalies averaged over the SE US in the CMIP5 models. The figures depict the SST in November from which region of the Pacific Ocean has a closer relationship with the following winter precipitation over the SE US in each CMIP5 model. In addition, the figures enable us to deduce the shift of the region where the strong relationship exists in the historical run under the global warming scenario, RCP8.5. In general, the positive correlation in the tropical central and eastern Pacific is flanked by negative correlation to the northwest and southwest in both the historical and RCP8.5 runs of all CMIP5 models. Interestingly, the reverse correlation pattern in CSIRO-Mk3-6-0 (Figure 8(b)), the closest relationship of the SST over the western Pacific with the SE US precipitation during wintertime, is evident. Higher correlation regions are shifted westward, mainly covering the Niño 4 and Niño 3.4 regions in the RCP8.5 run of GFDL-ESM2G.

3.3. SST Simulation in Past and Future Climate. The possible reason that many coupled climate models have exhibited unrealistic teleconnections between ENSO and extratropical circulation patterns is attributed to having poorly represented physical processes in the ENSO region in the models $[26,27]$.

Therefore, the CMIP5 models' performance of simulating the SST over the equatorial Pacific Ocean can also result in different climate impacts on the remote regions, especially the SE US. There have been numerous studies that examined the ability of CMIP5 models to simulate ENSO by comparing equatorial SST mean, standard deviation of Nino indices, ENSO spectral characteristics, and occurrence of ENSO events [28-32].

In this section, the SST over the equatorial Pacific Ocean in the CMIP5 models is further examined by comparing skewness of the SST from the historical run of CMIP5 models to that of the observed SST to reveal the reason for the models simulating different teleconnection patterns.

Figure 10 shows the skewness of November Niño indices, such as Niño 3, Niño 3.4, and Niño 4, derived from the observed ERSST from 1984 to 2010. ERSST displays decrease in skewness when moving from east to west across the equatorial Pacific. There exists the strongest positive skewness exceeding 0.6 over the Niño 3 region, indicating the warm SST anomalies are more probable than cold SST anomalies. It also shows the weakest positive skewness over the western Pacific. Although skewness of Niño indices is sensitive to the period selected, the feature of decreasing skewness from east to west across the Pacific is consistent with previous studies $[23,33]$.

By comparing the skewness of Niño indices obtained from the CMIP5 models to the observation shown in Figure 10, we can investigate which model has the highest credibility. Looking at the left panel in Figure 11, we can see that only the MIROC5 shows a pattern of decreasing skewness in positive sign when going from east to west across the equatorial Pacific consistent with the observation. The CCSM4 and GFDL-ESM2M have smaller positive skewness of SST over Niño 3.4 region than over Niño 3 region, but negative skewness over Niño 4 region. The NorESM1-M also has smaller positive skewness of SST over Niño 3.4 region than over Niño 3 region; however, it has relatively large negative skewness of SST over Niño 4 region, indicating that cold SST anomaly is dominant. On the other hand, the CSIRO-Mk3-6-0 and MPI-ESM-LR show a reverse pattern: skewness of SST in positive sign increases from east to west across the Pacific. Consequently, the reverse correlation 


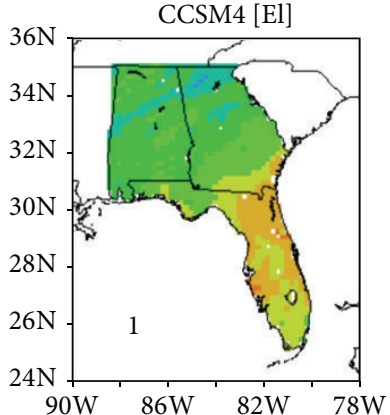

(a)

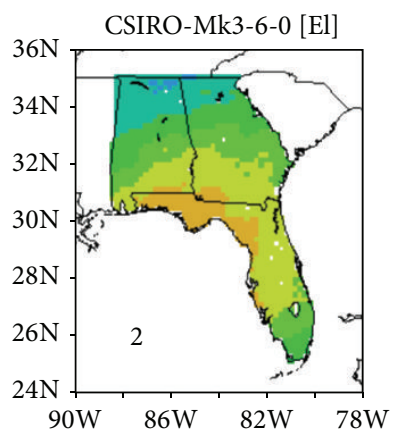

(b)

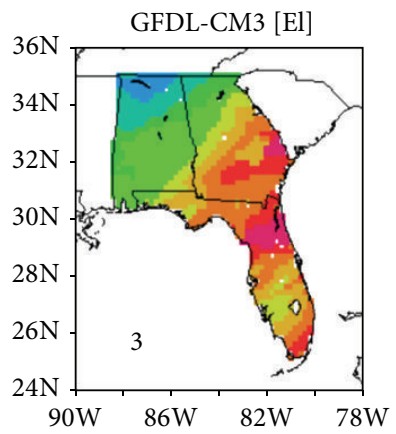

(c)

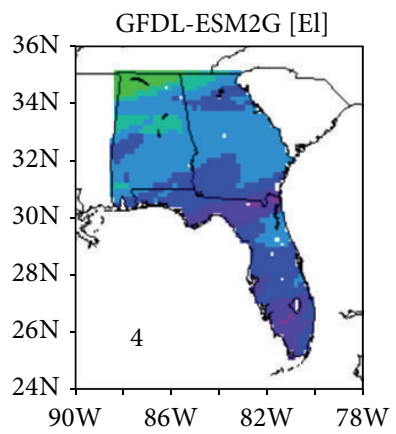

(d)

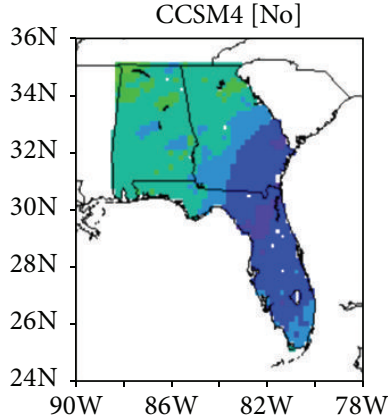

(e)

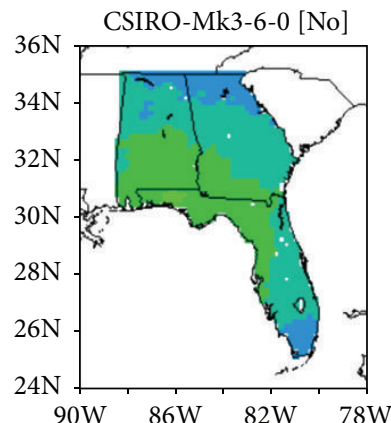

(f)

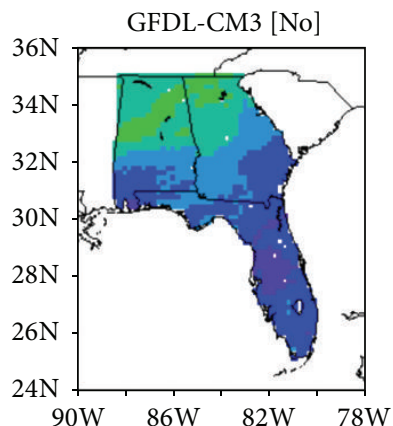

(g)

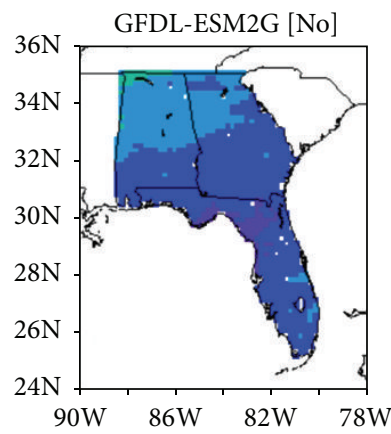

(h)
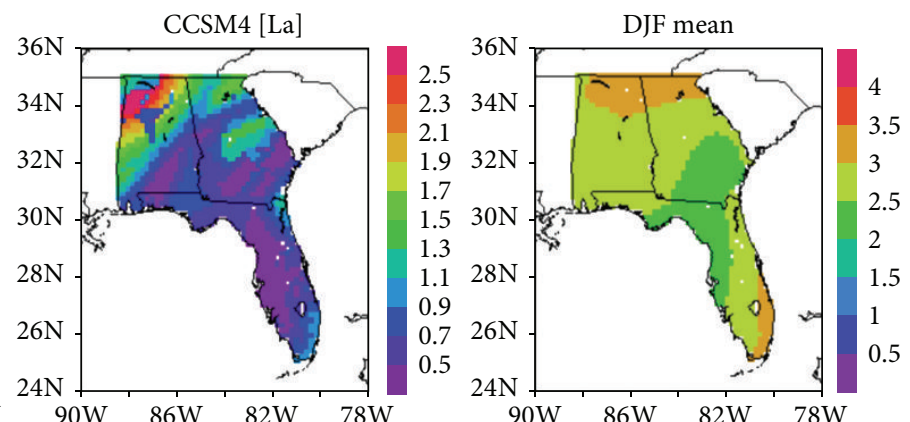

(i)

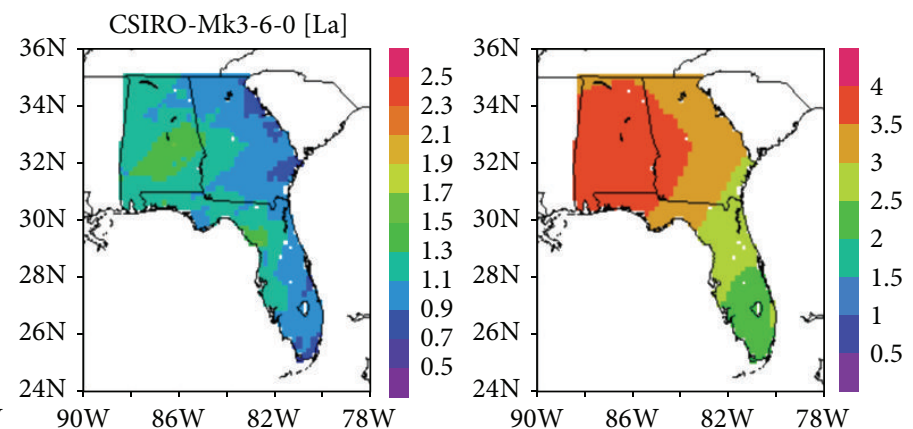

(j)

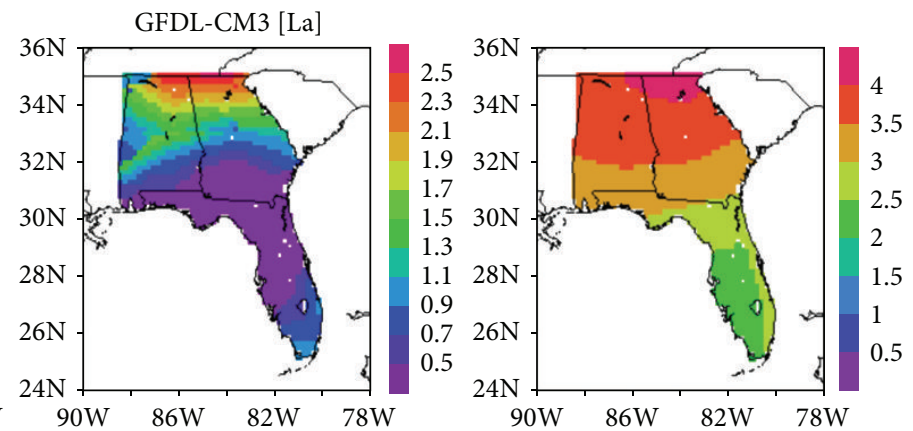

(k)
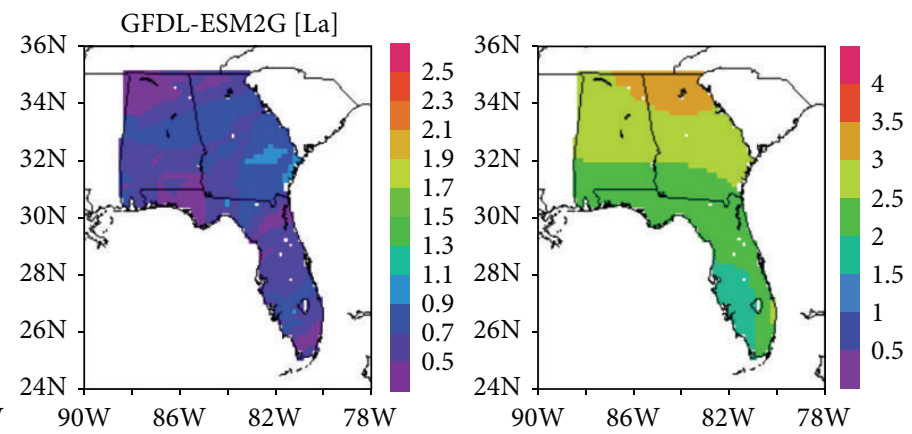

(l)

FIGURE 5: The 75th percentile of DJF mean daily precipitation anomalies (mm/day) distribution of El Niño ((a)-(d)), neutral ((e)-(h)), and La Niña ((i)-(l)) years in historical run of CMIP5 models 1-4. DJF mean daily precipitation is shown in the right column. 


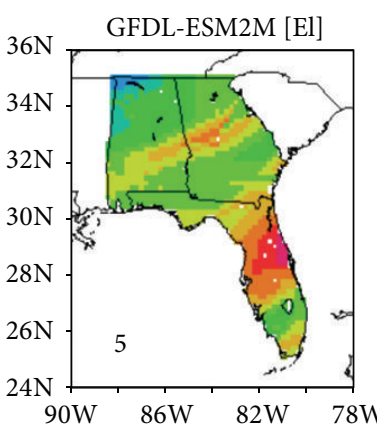

(a)

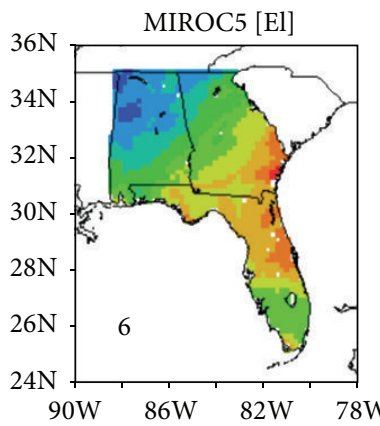

(b)

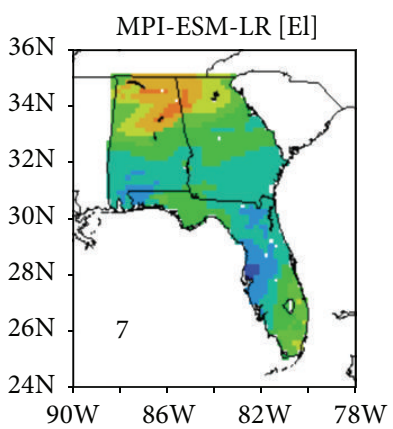

(c)

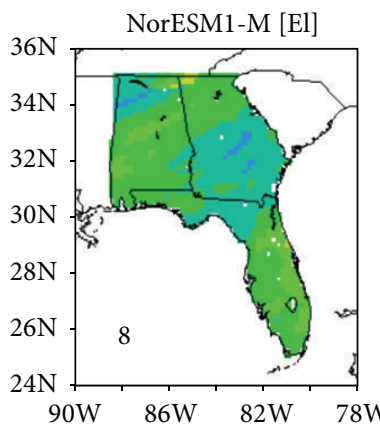

(d)

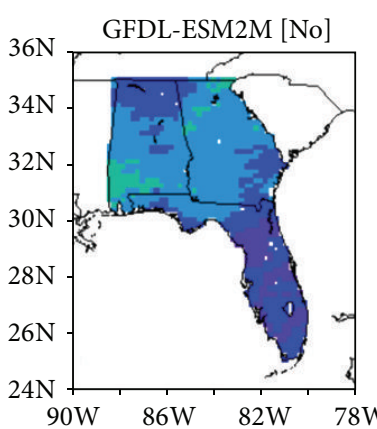

(e)

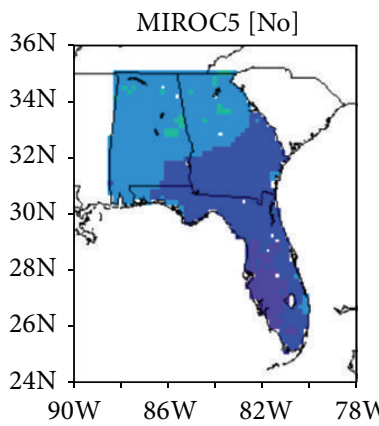

(f)

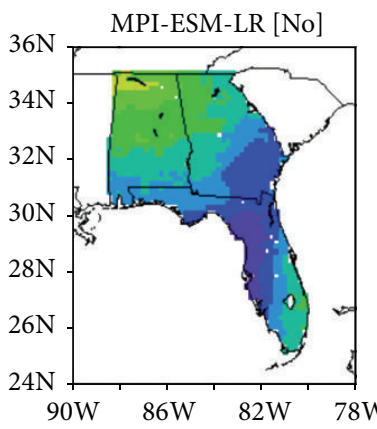

(g)

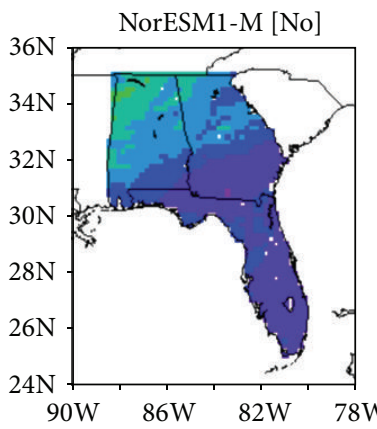

(h)

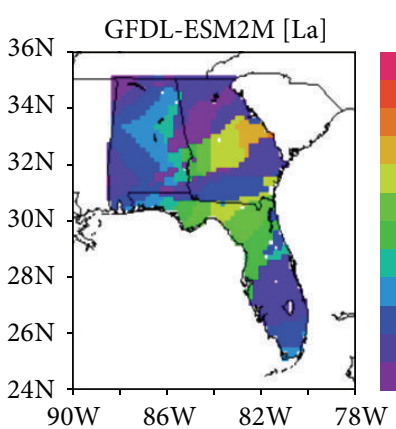

(i)
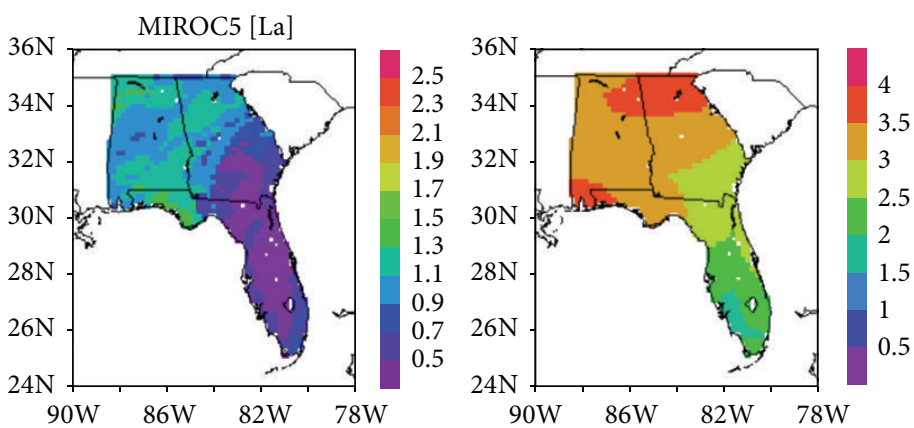

(j)
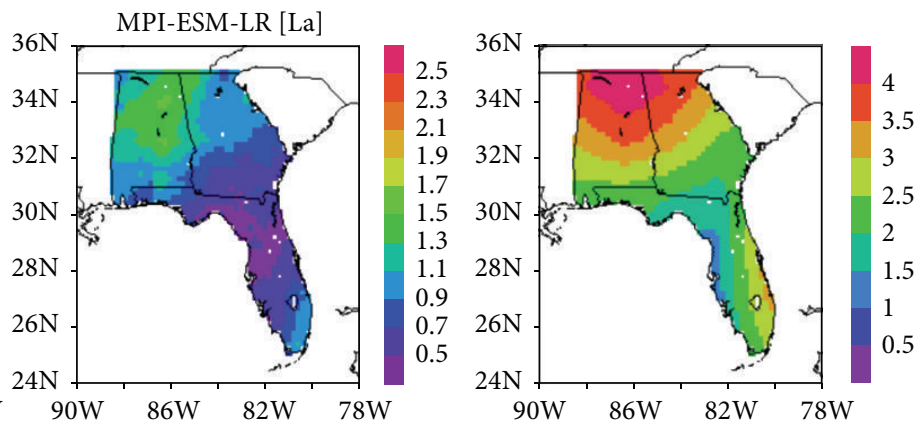

(k)

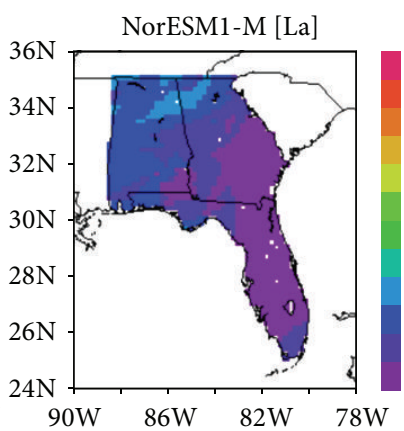

(l)

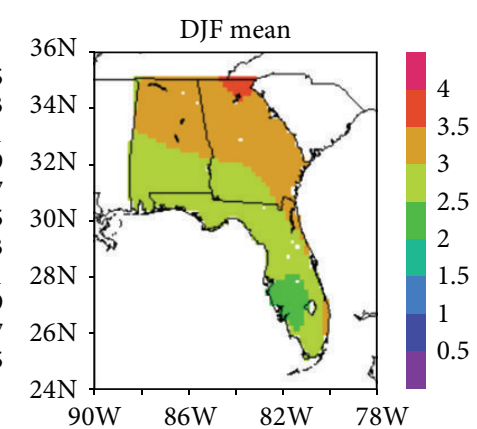

$$
\text { . }
$$




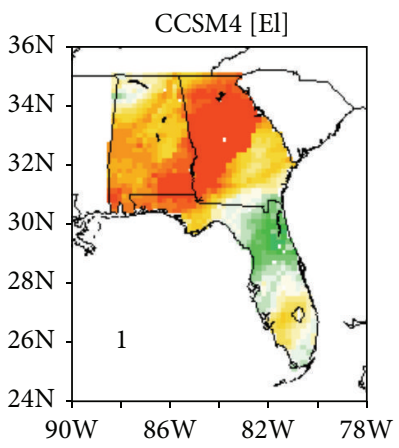

(a)

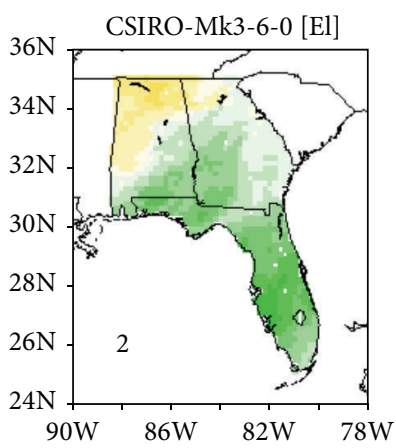

(b)

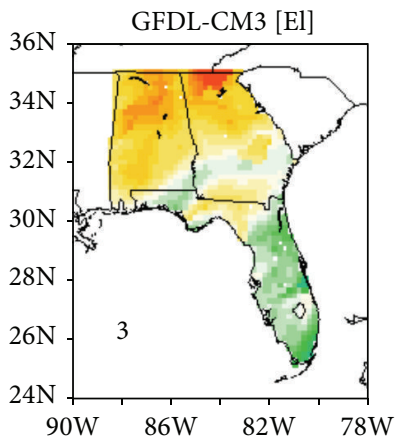

(c)

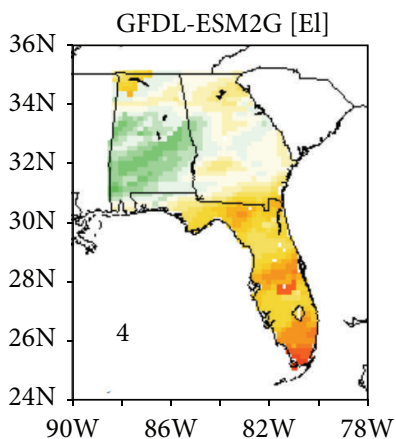

(d)

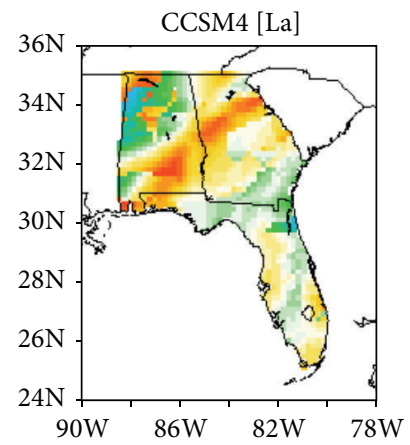

(e)

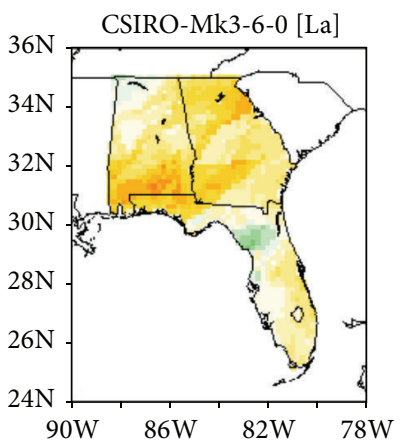

(f)

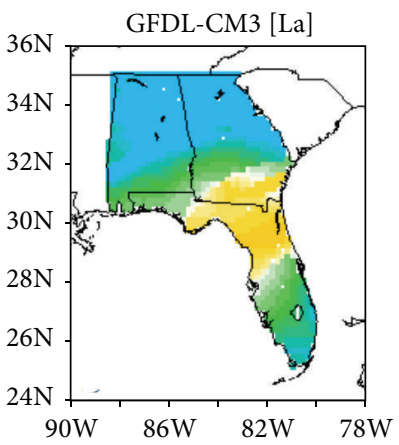

(g)

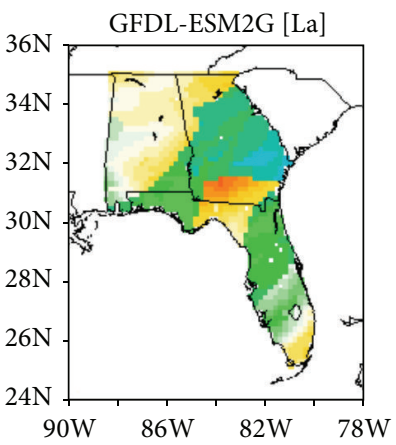

(h)

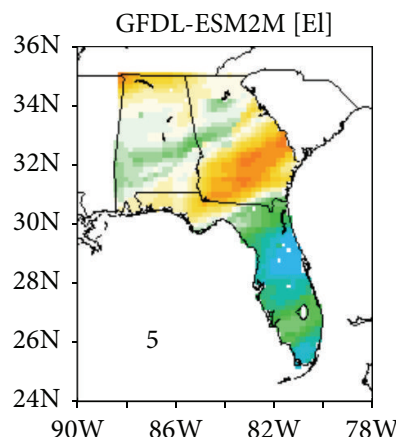

(i)

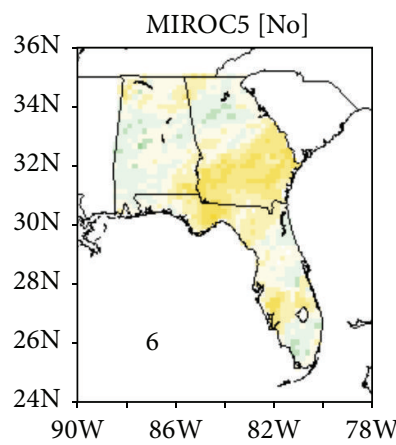

(j)

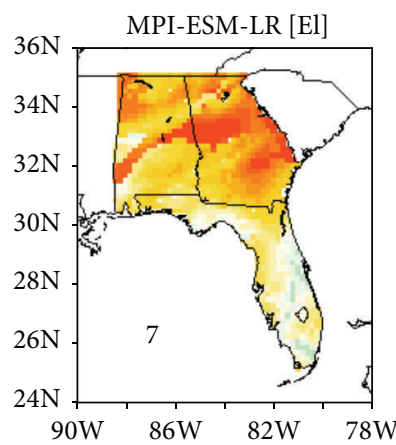

(k)

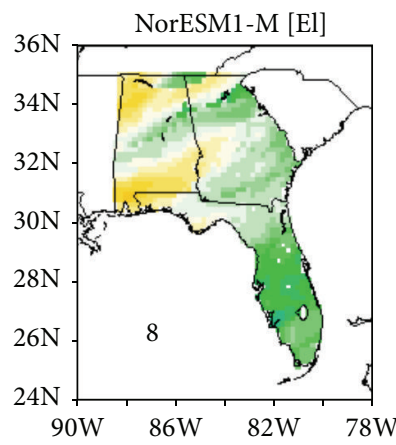

(1)

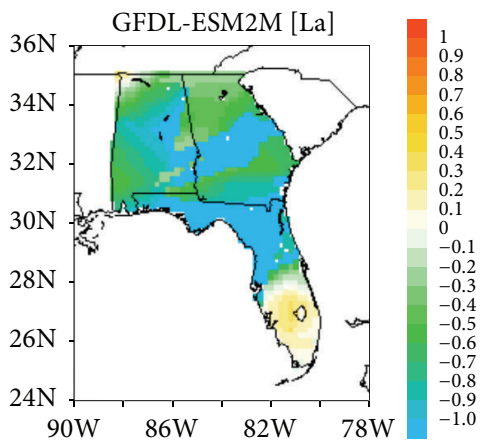

(m)

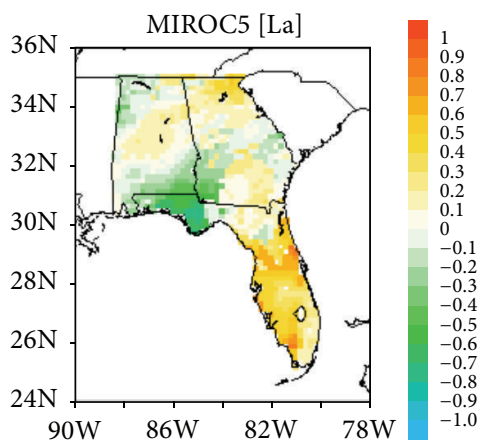

(n)

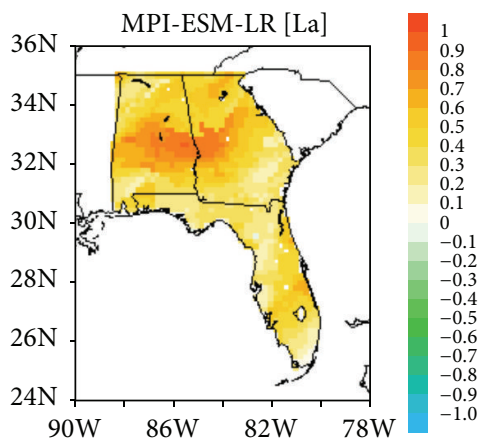

(o)

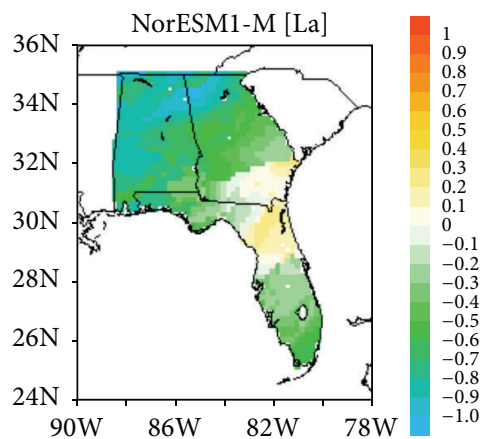

(p)

FIGURE 7: Difference of 75th percentile of DJF mean daily precipitation anomalies (mm/day) between RCP8.5 and historical run for El Niño ((a)-(d) and (i)-(l)) and La Niña ((e)-(h) and (m)-(p)). 


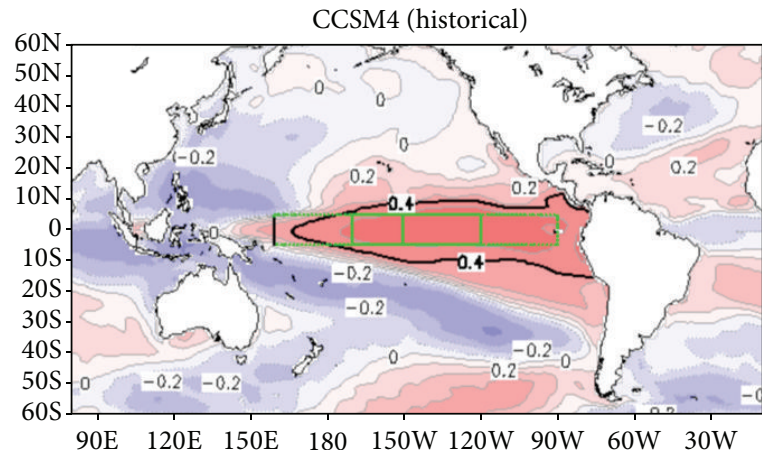

(a)

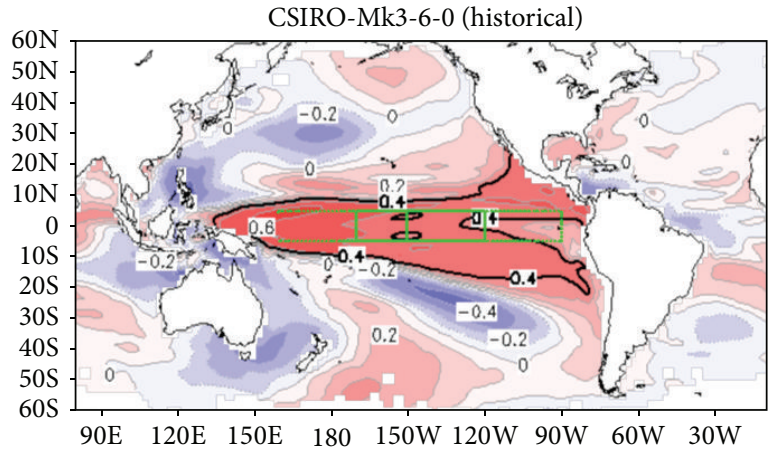

(b)

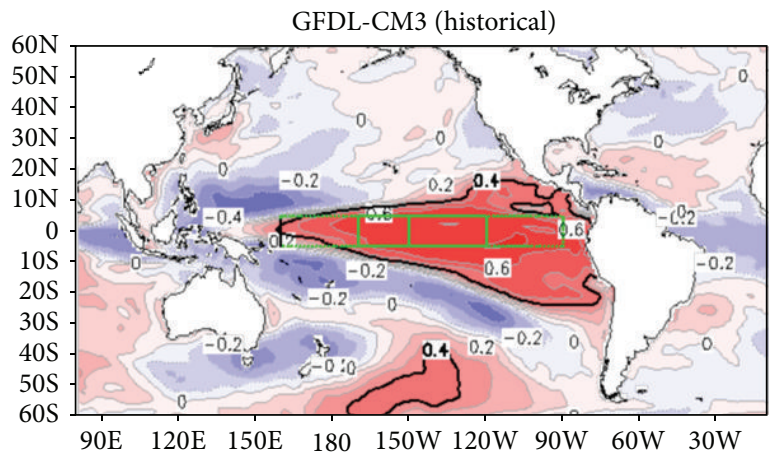

(c)

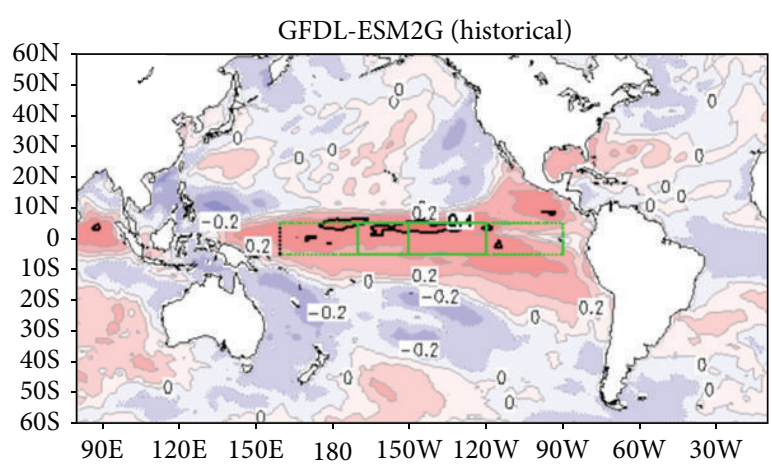

(d)

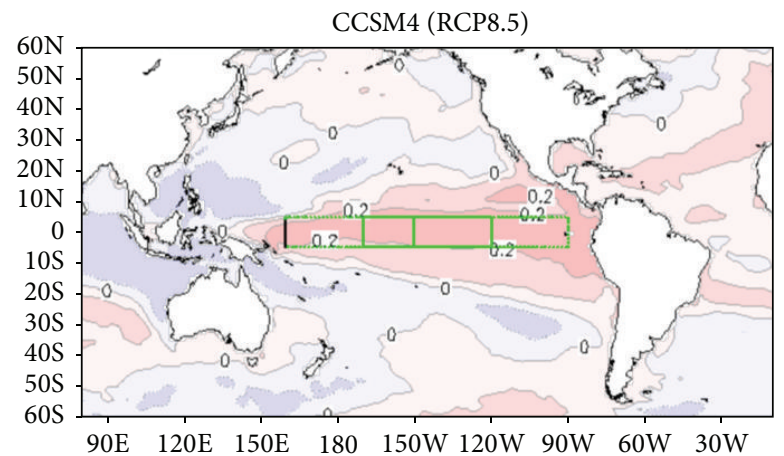

(e)

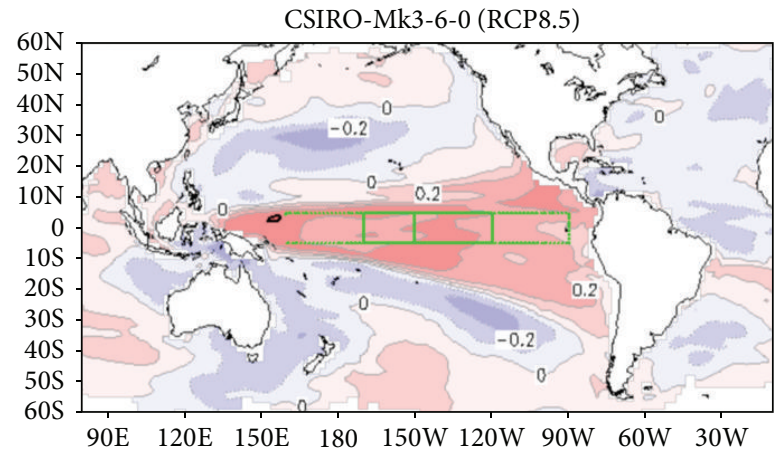

(f)

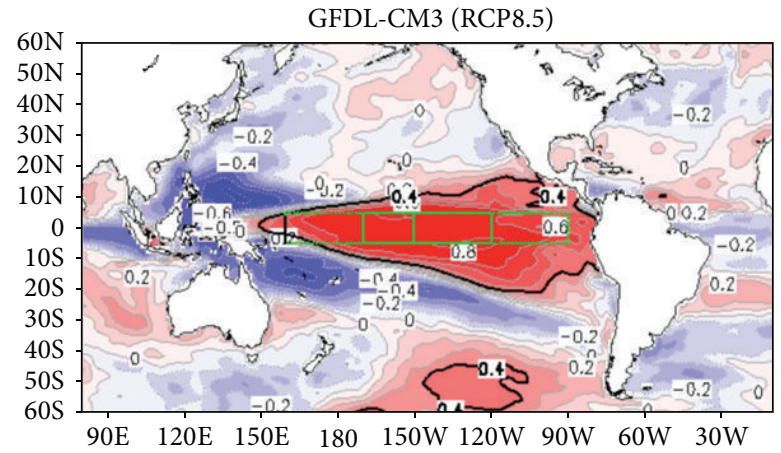

(g)

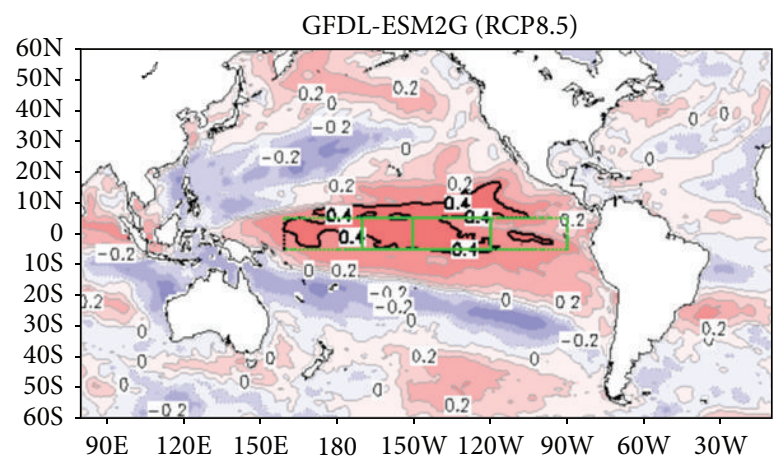

(h)

FIGURE 8: Ensemble member averaged correlation between the November SST and the DJF mean daily rainfall anomaly averaged over the SE US for CMIP5 models 1-4 (historical run: (a)-(d), RCP8.5 run: (e)-(h)). Locations of the Niño 3, 3.4, and 4 regions are marked with rectangular box from left, middle, and right, respectively. The 0.4 contour is thickened for better comparison. 


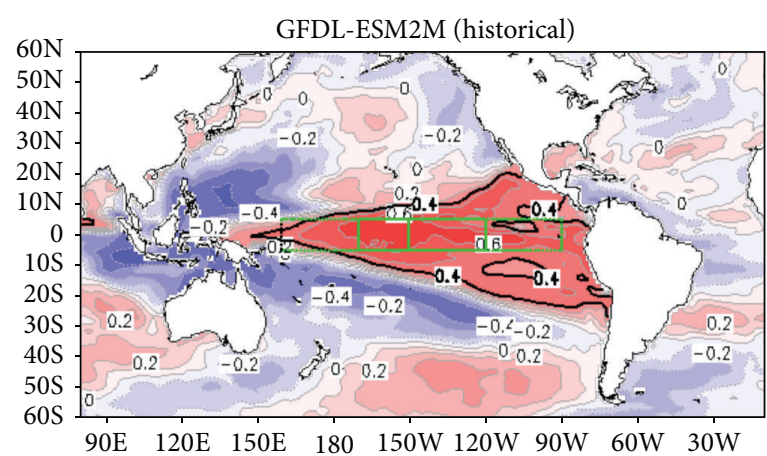

(a)

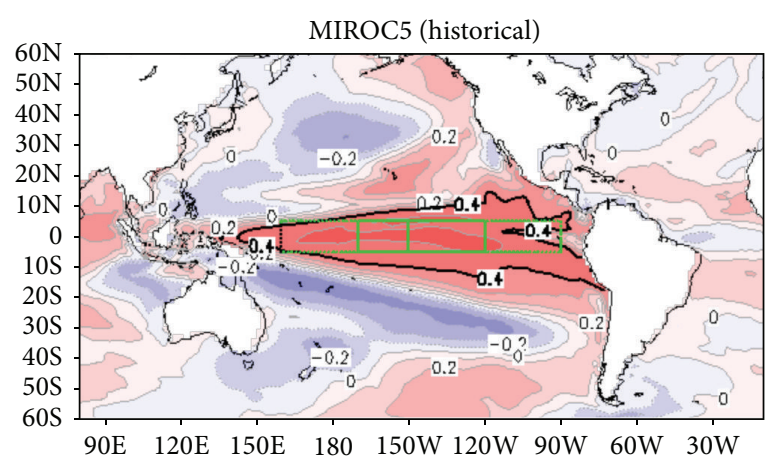

(b)

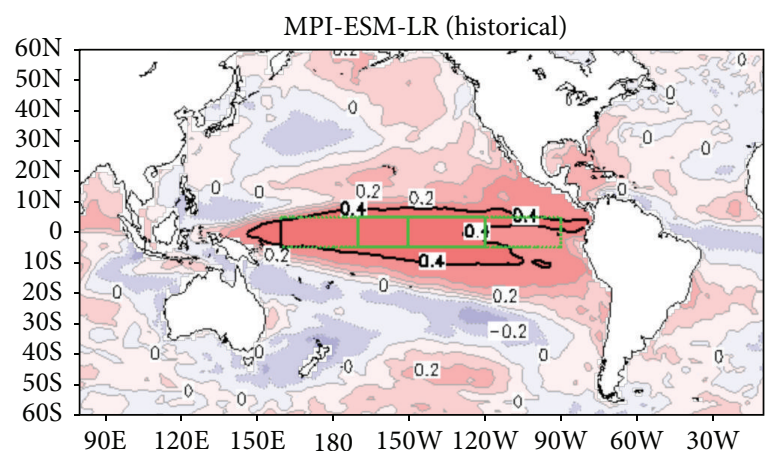

(c)

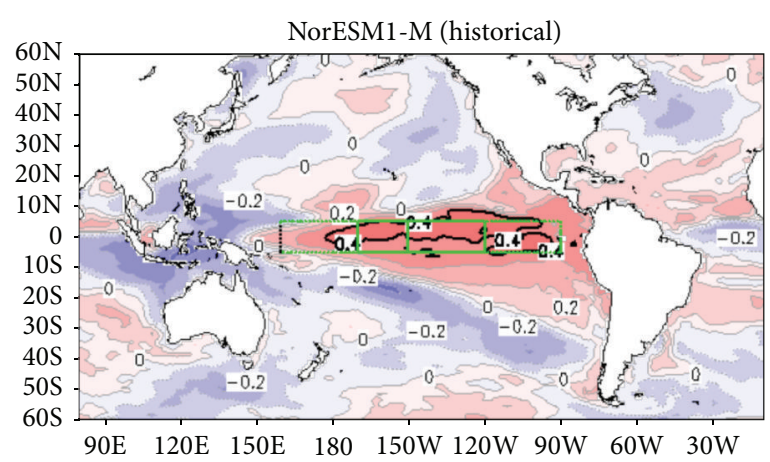

(d)

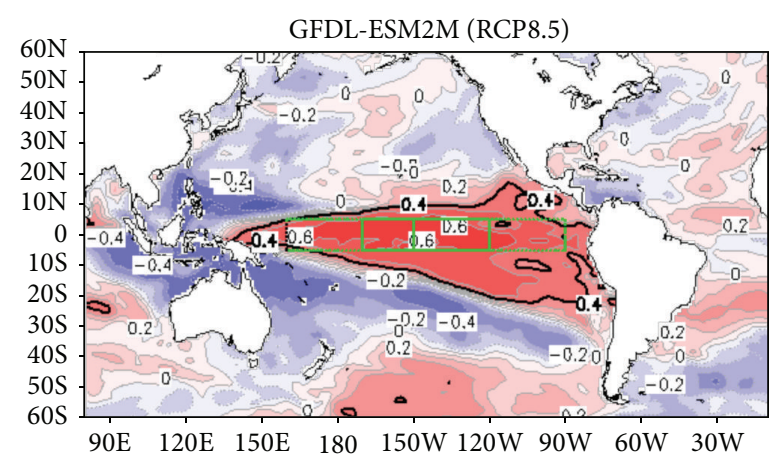

(e)

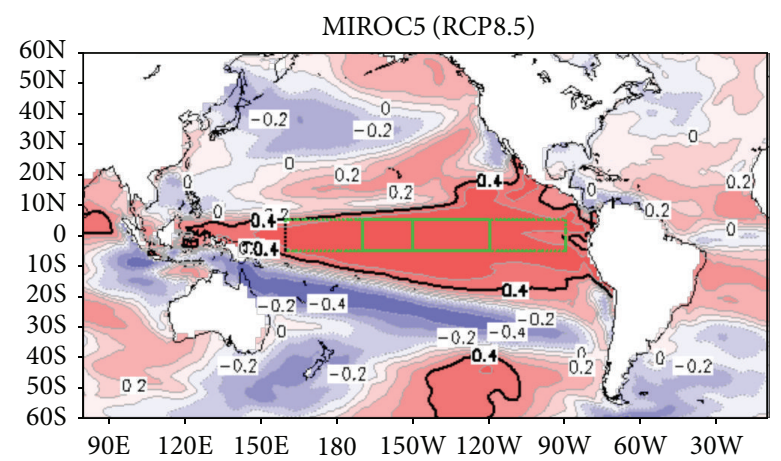

(f)

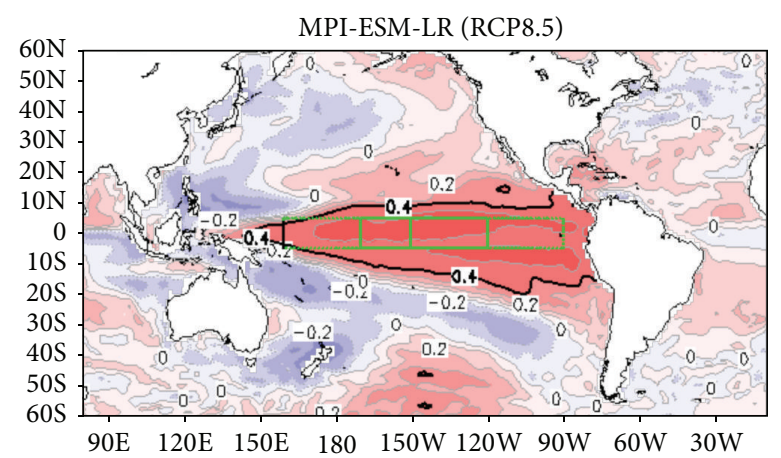

(g)

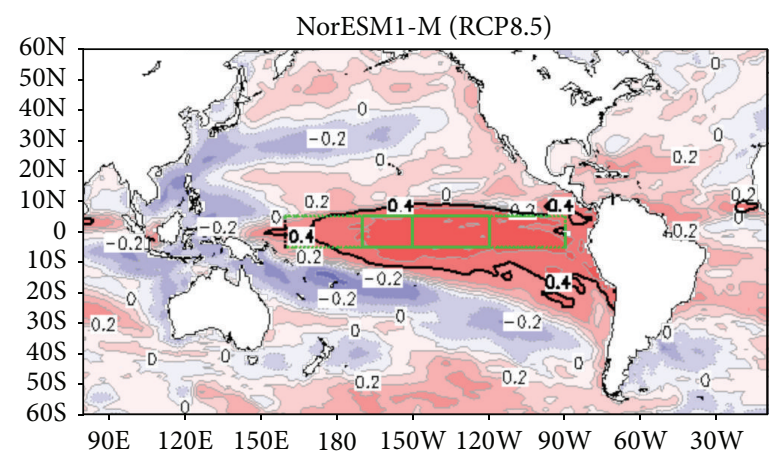

(h)

FIgURE 9: Same as Figure 8, but for CMIP5 models 5-8. 


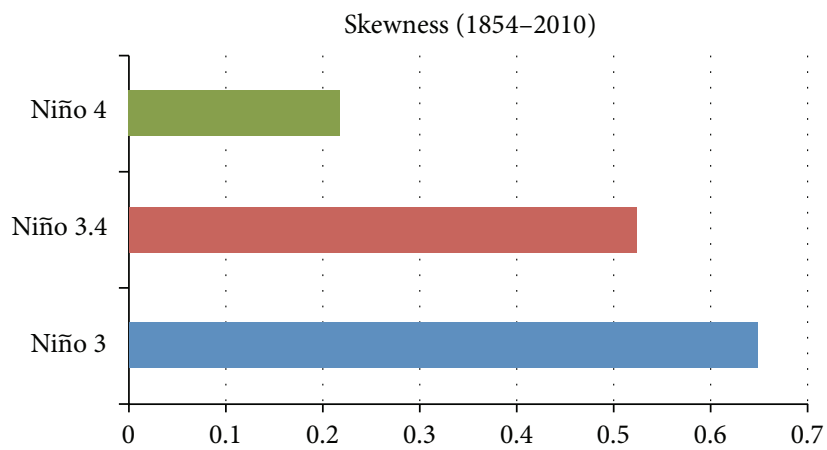

FIGURE 10: Skewness of November ENSO indices of ERSST observation for the period from 1854 to 2010.

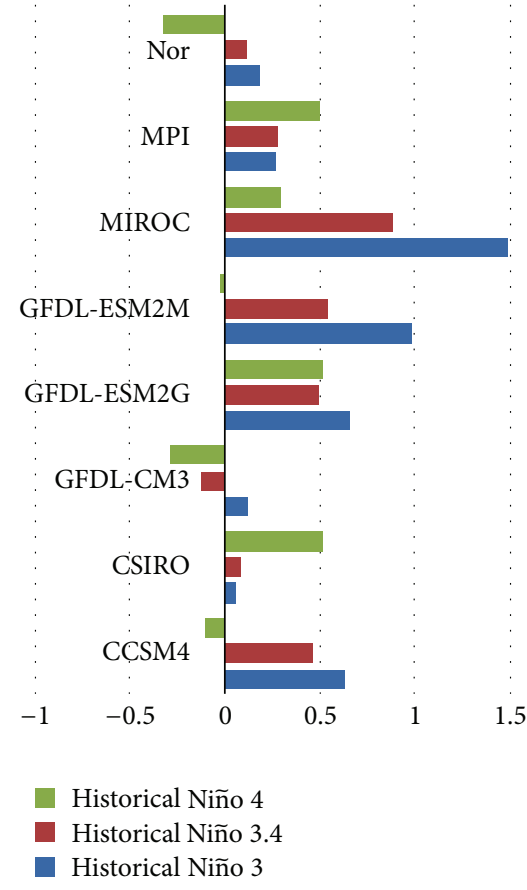

(a)

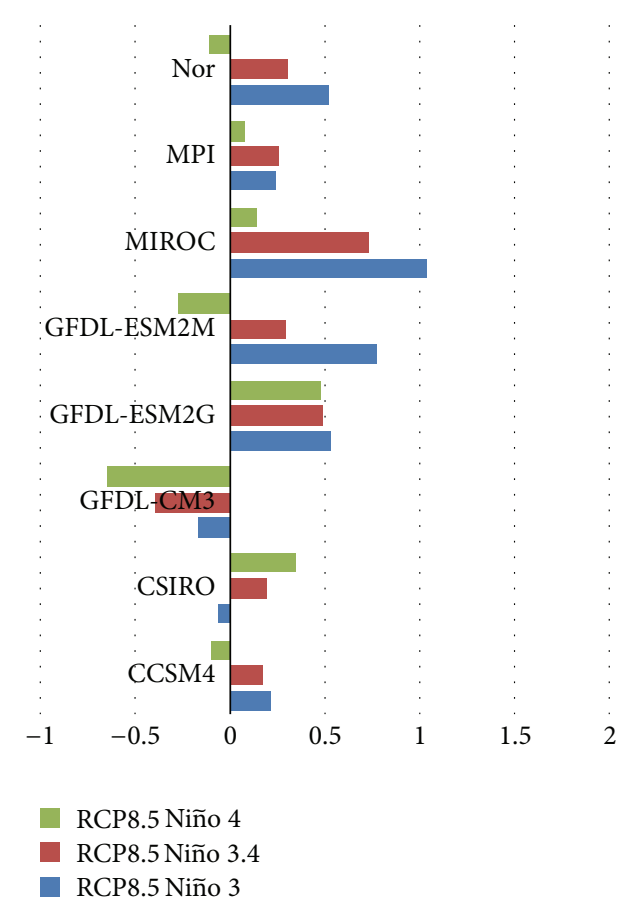

(b)

FIGURE 11: Ensemble member averaged skewness of November ENSO indices for historical (a) and RCP8.5 (b) experiments, respectively.

Florida peninsula, differing from the observation (Figures 2 and 3).

Although the SST from the historical run of CMIP5 models in this study shows different characteristics of skewness from those observed in Figure 10, the models tend to maintain the overall feature of skewness from the historical run in the future simulation. Five of the eight models show a decrease in the skewness of SST over the Niño 3 region in the RCP8.5. Moreover, the positive skewness over the Niño 3 region in the historical runs changes to negative in the RCP8.5.

\section{Conclusion and Discussion}

In this study, we inquire whether the current teleconnection characteristics between winter precipitation over the SE US and the tropical Pacific SST will persist in the future under the global warming scenario simulated by current state-of-the-art climate models. The credibility of CMIP5 models regarding the simulation of the regional scale climate variability is validated by applying the robust teleconnection feature to the assessment in order to obtain confidence in future climate prediction. We find out that most of the 8 models selected in this study show a positive correlation between the November Niño 3 SST and the DJF mean daily precipitation anomalies over the SE US, consistent with the observation. Although the global models in the CMIP5 are capable of simulating the regional response of the teleconnection, it is of interest to note that one partial change in the model could contribute to different teleconnection patterns.

In the RCP8.5 run, all of the models maintain the positive and slightly increased correlation patterns. However, the degree of change in the relationship differs from domains under the climate change scenario, RCP8.5. Whereas the SST over Niño 3 region accounts for the largest portion of variance 
of rainfall in Florida in the observation as well as in the historical run of the models (NorESM1-M, MIROC5, GFDLESM2M, GFDL-CM3, and CCSM4), the models have an increased portion of variance in Alabama and Georgia in the RCP8.5 regarding the winter precipitation that is attributed to the SST over Niño 3 region.

To analyze the impact of ENSO on the wintertime extreme rainfall over the SE US, we focus on the 75th percentile from the right tail of DJF daily rainfall anomaly distribution in terms of ENSO phases. The greater value of the 75th percentile of rainfall for El Niño is mostly found over Florida, differing from the DJF mean daily precipitation pattern in which maximum DJF mean daily rainfall area is mostly located over the northern SE US, spanning Alabama and Georgia. In the same way, the smaller value of the 75th percentile of rainfall for La Niña is mostly located over Florida. The models that show a greater correlation coefficient in the RCP8.5 than in the historical run have heavier rainfall during El Niño events in the future run. It is noteworthy that the increase in extreme rainfall amount during El Niño events tends to be dominant over the northern regions of the SE US, including Alabama and Georgia under the climate change.

We have found that the CMIP5 models' performance of simulating the SST over the equatorial Pacific Ocean affects the climate impact on the SE US. By comparing the skewness of Niño indices obtained from the historical run of CMIP5 models to that of the observation, we assessed which model has the highest credibility. It turns out that the models with poor realization of skewness, such as CSIRO-Mk3-60, GFDL-ESM2G, and MPI-ESM-LR, fail to simulate the realistic teleconnection pattern and have lower confidence in future climate prediction.

We also have shown the northward shift of the ENSO teleconnection pattern over the SE US. This finding refines the results of previous studies on the change of the teleconnections over the North Pacific and North America associated with El Niño events in a future warmer climate $[16,34,35]$. The change could be attributed not only to changes in the amplitude and the location of the convection center of the El Niño events themselves but also to an altered base-state, midlatitude atmospheric circulation due to the increase of greenhouse gases. Furthermore, rainfall is the economically important climate variable for the SE US, a region of major agricultural production. The projected RCP8.5 teleconnections between ENSO and precipitation patterns found in this study will provide farmers in the SE US northern regions (Alabama and Georgia) with additional knowledge about the projected seasonal climate in the region. According to the RCP8.5 projections regarding the strength of the studied teleconnection, yield predictability of corn [35], cotton [36], peanuts [37], and citrus [38], among the main crops in the regions, will increase and allow farmers in the region to make better climate based decisions.

\section{Conflict of Interests}

The authors declare that there is no conflict of interests regarding the publication of this paper.

\section{Acknowledgment}

This work was supported by a grant from the Agriculture and Food Research Initiative of the USDA National Institute of Food and Agriculture (NIFA), Grant no. FLAW-2011-00828 (EaSM Project).

\section{References}

[1] K. E. Taylor, R. J. Stouffer, and G. A. Meehl, "An overview of CMIP5 and the experiment design," Bulletin of the American Meteorological Society, vol. 93, no. 4, pp. 485-498, 2012.

[2] J.-P. Michael, V. Misra, and E. Chassignet, "The El Niño and Southern Oscillation in the historical centennial integrations of the new generation of climate models," Regional Environmental Change, vol. 13, no. 1, pp. 121-130, 2013.

[3] R. Knutti and J. Sedláček, "Robustness and uncertainties in the new CMIP5 climate model projections," Nature Climate Change, vol. 3, no. 4, pp. 369-373, 2013.

[4] B. Langenbrunner and J. D. Neelin, "Analyzing ENSO teleconnections in CMIP models as a measure of model fidelity in simulating precipitation," Journal of Climate, vol. 26, no. 13, pp. 4431-4446, 2013.

[5] J. Liu, B. Wang, M. A. Cane, S.-Y. Yim, and J.-Y. Lee, "Divergent global precipitation changes induced by natural versus anthropogenic forcing," Nature, vol. 493, no. 7434, pp. 656-659, 2013.

[6] K. Ingram, K. Dow, L. Carter, and J. Anderson, Climate of the Southeast United States: Variability, Change, Impacts, and Vulnerability, Island Press, Washington, DC, USA, 2013.

[7] USDA and National Agricultural Statistics Service, "Crop Values 2012 Summary. February 2013," pp. 49, 2013.

[8] S. Cocke, T. LaRow, and D. Shin, "Seasonal rainfall predictions over the southeast United States using the Florida State University nested regional spectral model," Journal of Geophysical Research, vol. 112, no. D4, 2007.

[9] K. C. Mo, "Interdecadal modulation of the impact of ENSO on precipitation and temperature over the United States," Journal of Climate, vol. 23, no. 13, pp. 3639-3656, 2010.

[10] L. Stefanova, P. Sura, and M. Griffin, "Quantifying the nongaussianity of wintertime daily maximum and minimum temperatures in the southeast," Journal of Climate, vol. 26, no. 3, pp. 838-850, 2013.

[11] T. Eichler and W. Higgins, "Climatology and ENSO-related variability of North American extratropical cyclone activity," Journal of Climate, vol. 19, no. 10, pp. 2076-2093, 2006.

[12] F. S. Royce, C. W. Fraisse, and G. A. Baigorria, "ENSO classification indices and summer crop yields in the Southeastern USA," Agricultural and Forest Meteorology, vol. 151, no. 7, pp. 817-826, 2011.

[13] V. E. Cabrera, C. W. Fraisse, D. Letson, G. Podestá, and J. Novak, "Impact of climate information on reducing farm risk by optimizing crop insurance strategy," Transactions of the ASABE, vol. 49, no. 4, pp. 1223-1233, 2006.

[14] A. Gershunov and T. P. Barnett, "Interdecadal modulation of ENSO teleconnections," Bulletin of the American Meteorological Society, vol. 79, no. 12, pp. 2715-2725, 1998.

[15] R. Joseph and S. Nigam, "ENSO evolution and teleconnections in IPCC's twentieth-century climate simulations: realistic representation?" Journal of Climate, vol. 19, no. 17, pp. 4360-4377, 2006. 
[16] W. Cai, A. Sullivan, and T. Cowan, "Rainfall teleconnections with indo-pacific variability in the WCRP CMIP3 models," Journal of Climate, vol. 22, no. 19, pp. 5046-5071, 2009.

[17] H. F. Diaz, M. P. Hoerling, and J. K. Eischeid, "ENSO variability, teleconnections and climate change," International Journal of Climatology, vol. 21, no. 15, pp. 1845-1862, 2001.

[18] J.-S. Kug, S.-I. An, Y.-G. Ham, and I.-S. Kang, "Changes in El Niño and La Niña teleconnections over North Pacific-America in the global warming simulations," Theoretical and Applied Climatology, vol. 100, no. 3, pp. 275-282, 2010.

[19] J. W. Jones, J. W. Hansen, F. S. Royce, and C. D. Messina, "Potential benefits of climate forecasting to agriculture," Agriculture, Ecosystems and Environment, vol. 82, no. 1-3, pp. 169-184, 2000.

[20] G. Cressman, "An operational objective analysis system," Monthly Weather Review, vol. 87, pp. 367-374, 1959.

[21] Y.-K. Lim, S. Cocke, D. W. Shin, J. T. Schoof, T. E. LaRow, and J. J. O'Brien, "Downscaling large-scale NCEP CFS to resolve finescale seasonal precipitation and extremes for the crop growing seasons over the southeastern United States," Climate Dynamics, vol. 35, no. 2, pp. 449-471, 2010.

[22] D. Hanley, M. Bourassa, J. O’Brien, S. Smith, and E. Spade, "A quantitative evaluation of ENSO indices," Journal of Climate, vol. 16, pp. 1249-1258, 2003.

[23] G. Burgers and D. Stephenson, "The "normality" of El Niño," Geophysical Research Letters, vol. 26, no. 8, pp. 1027-1030, 1999.

[24] J. P. Dunne, J. G. John, S. Shevliakova et al., "GFDL's ESM2 global coupled climate-carbon earth system models. Part II: carbon system formulation and baseline simulation characteristics," Journal of Climate, vol. 26, no. 7, pp. 2247-2267, 2013.

[25] M. P. Hoerling, A. Kumar, and M. Zhong, "El Niño, La Niña, and the nonlinearity of their teleconnections," Journal of Climate, vol. 10, no. 8, pp. 1769-1786, 1997.

[26] K. A. Rao and K. R. Sperber, "ENSO simulation in coupled ocean-atmosphere models: are the current models better?" Climate Dynamics, vol. 27, no. 1, pp. 1-15, 2006.

[27] M. J. DeFlorio, D. W. Pierce, D. R. Cayan, and A. J. Miller, "Western U.S. extreme precipitation events and their relation to ENSO and PDO in CCSM4," Journal of Climate, vol. 26, no. 12, pp. 4231-4243, 2013.

[28] A. S. Taschetto, A. S. Gupta, N. C. Jourdain, A. Santoso, C. C. Ummenhofer, and M. H. England, "Cold tongue and warm pool ENSO Events in CMIP5: mean state and future projections," Journal of Climate, vol. 27, no. 8, pp. 2861-2885, 2014.

[29] H. Bellenger, E. Guilyardi, J. Leloup, M. Lengaigne, and J. Vialard, "ENSO representation in climate models: from CMIP3 to CMIP5," Climate Dynamics, vol. 42, no. 7-8, pp. 1999-2018, 2014.

[30] S.-W. Yeh, Y.-G. Ham, and J.-Y. Lee, "Changes in the tropical pacific SST trend from CMIP3 to CMIP5 and its implication of ENSO," Journal of Climate, vol. 25, no. 21, pp. 7764-7771, 2012.

[31] S.-W. Yeh, Y.-G. Ham, and B. P. Kirtman, "A possible explanation on the changes in the spatial structure of ENSO from CMIP3 to CMIP5," Geophysical Research Letters, vol. 41, no. 1, pp. 140-145, 2014.

[32] S. T. Kim and J.-Y. Yu, "The two types of ENSO in CMIP5 models," Geophysical Research Letters, vol. 39, no. 11, 2012.

[33] S.-I. An, "A review of interdecadal changes in the nonlinearity of the El Niño-Southern oscillation," Theoretical and Applied Climatology, vol. 97, no. 1-2, pp. 29-40, 2009.

[34] G. A. Meehl, H. Teng, and G. Branstator, "Future changes of El Niño in two global coupled climate models," Climate Dynamics, vol. 26 , no. 6, pp. 549-566, 2006.
[35] C. J. Martinez, G. A. Baigorria, and J. W. Jones, "Use of climate indices to predict corn yields in southeast USA," International Journal of Climatology, vol. 29, no. 11, pp. 1680-1691, 2009.

[36] G. A. Baigorria, M. Chelliah, K. C. Mo et al., "Forecasting cotton yield in the southeastern United States using coupled global circulation models," Agronomy Journal, vol. 102, no. 1, pp. 187196, 2010.

[37] D. Shin, G. Baigorria, Y.-K. Lim et al., "Assessing maize and peanut yield simulations with various seasonal climate data in the Southeastern United States," Journal of Applied Meteorology and Climatology, vol. 49, no. 4, pp. 592-603, 2010.

[38] C. C. Romero, M. D. Dukes, G. A. Baigorria, and R. Cohen, "Comparing theoretical irrigation requirement and actual irrigation for citrus in Florida," Agricultural Water Management, vol. 96, no. 3, pp. 473-483, 2009. 

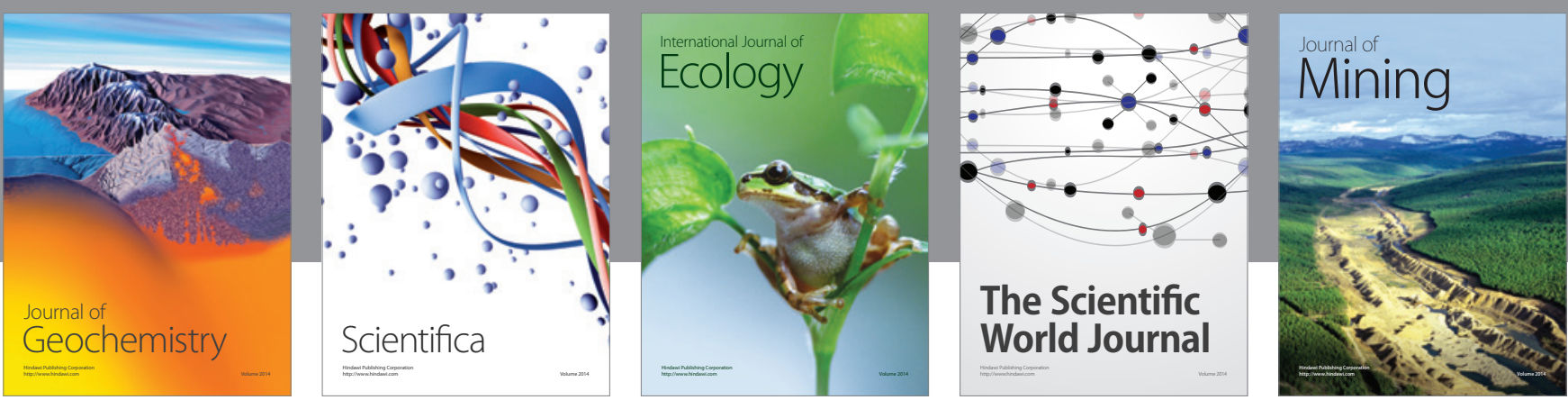

The Scientific World Journal
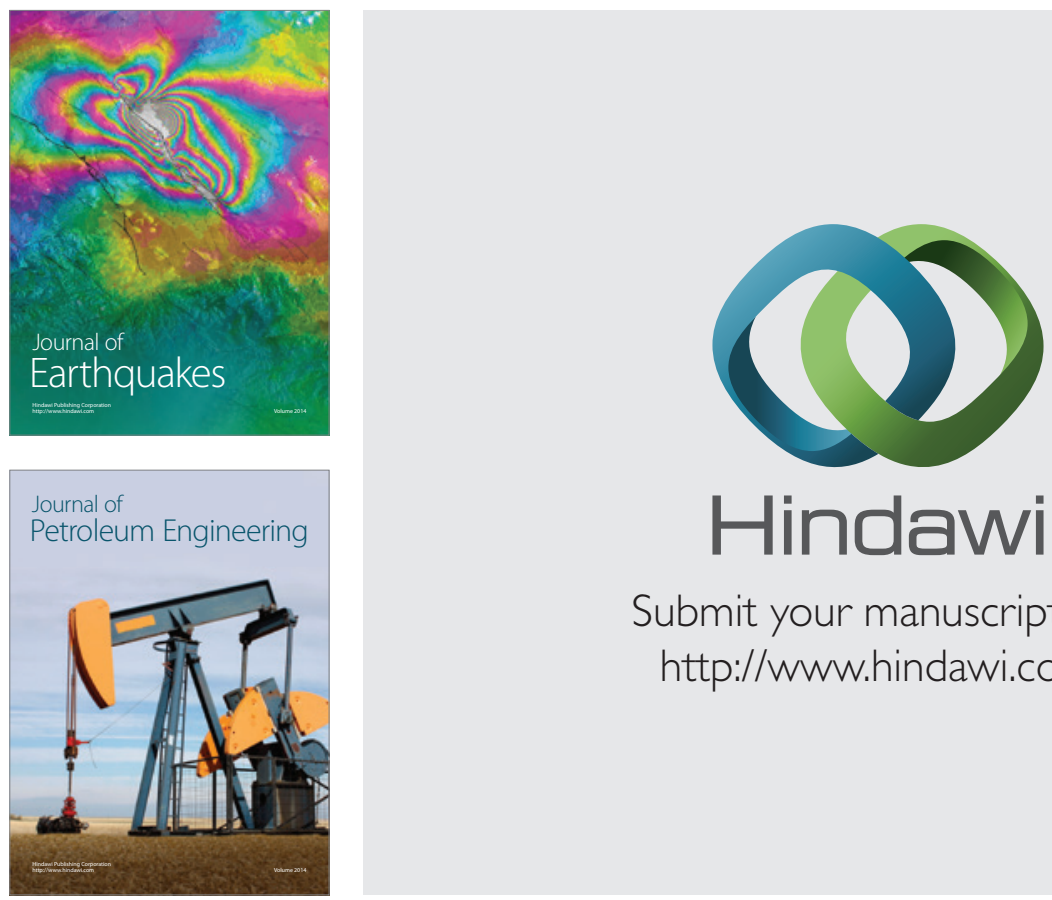

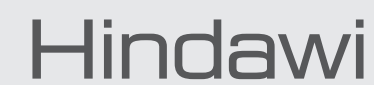

Submit your manuscripts at

http://www.hindawi.com
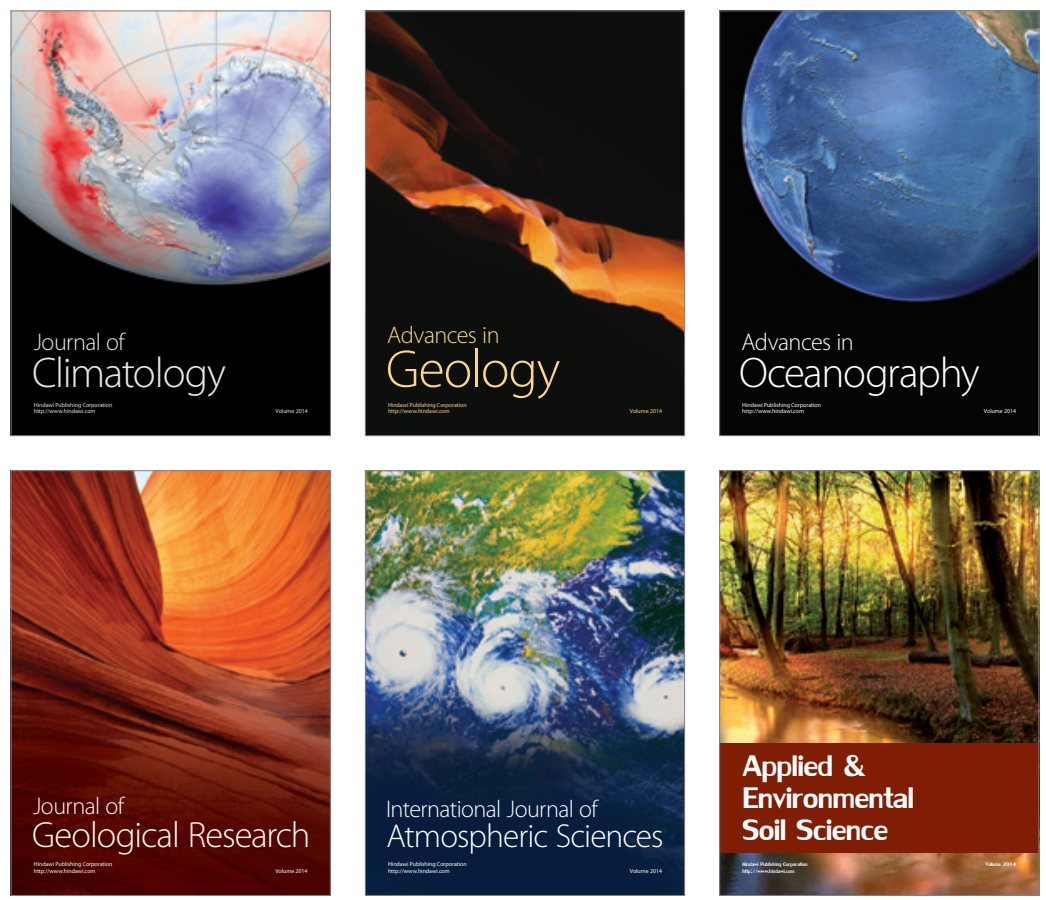
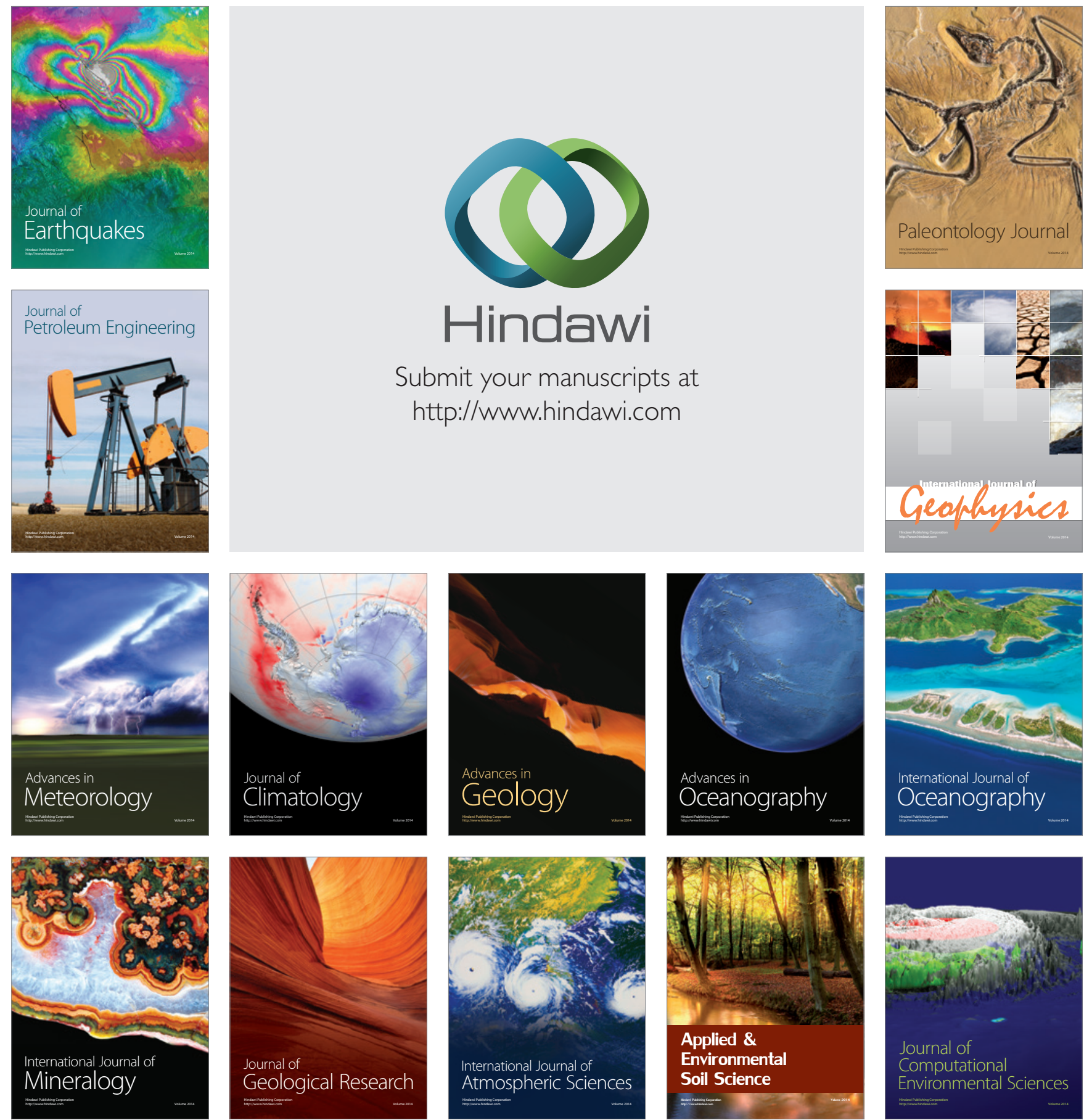